\title{
Efficient Monetary Policy Design Near Price Stability
}

\author{
Athanasios Orphanides and Volker Wieland* \\ Board of Governors of the Federal Reserve System
}

December 1999

\begin{abstract}
We study the design of monetary policy in a low inflation environment taking into account the limitations imposed by the zero bound on nominal interest rates. Using numerical dynamic programming methods, we compute optimal policies in a simple, calibrated openeconomy model and evaluate the effect of the liquidity trap generated by the zero bound. We consider the possibility that the quantity of base money may affect output and inflation even when the interest rate is constrained at zero and explicitly account for the substantial degree of uncertainty regarding such quantity effects. As an example of such a quantity effect, we focus on the portfolio balance channel through which changes in relative money supplies influence the exchange rate. We find that the optimal policy near price stability is asymmetric, that is, as inflation declines, policy turns expansionary sooner and more aggressively than would be optimal in the absence of the zero bound. As a consequence, the average level of inflation is biased upwards. These results indicate that policymakers are faced with a tradeoff between the level of inflation and economic stabilization performance when the economy is operating near the zero bound. Finally, we discuss operational issues associated with the interpretation and implementation of policy at the zero bound in relation to the recent situation in Japan.
\end{abstract}

KEYwORDS: Price stability, zero bound, optimal monetary policy, liquidity trap.

JEL Classification System: E31, E52, E58, E61

Correspondence: Orphanides: Division of Monetary Affairs, Board of Governors of the Federal Reserve System, Washington, D.C. 20551, USA. Tel.: (202) 452-2654, e-mail: aorphanides@frb.gov. Wieland: Division of Monetary Affairs, Board of Governors of the Federal Reserve System, D.C. 20551, USA. Tel.: (202) 736-5620, e-mail: vwieland@frb.gov.

${ }^{*}$ We would like to thank Chris Hanes, Fumio Hayashi, Jim Morsink, Kiyohiko Nishimura, participants of the NBER/CEPR/TCER Conference on Monetary Policy in a Low Inflation Environment, Tokyo, December 16-17, 1999, and colleagues at the Federal Reserve, especially Dick Porter, for helpful discussions and comments. The opinions expressed are those of the authors and do not necessarily reflect views of the Board of Governors of the Federal Reserve System or its staff. 


\section{Introduction}

Since February 12, 1999, the Bank of Japan has taken the unprecedented step of maintaining overnight interest rates "as low as possible." This action was the latest in a series of policy easings that started in 1991 and have brought the Bank's discount rate down to a mere 50 basis points and short-term interest rates to near zero since September 1995. In April, 1999 the Policy Board of the Bank took the additional step of announcing a commitment to maintain this "zero interest rate policy" until deflationary tendencies in the Japanese economy end, ensuring that policy should be expected to remain unchanged for quite some time. As the Bank's Deputy Governor Yamaguchi (1999a) observed recently, this policy has been successful thus far in that “... the Japanese economy has, if only barely, escaped deflation." He also noted, however, that despite these unprecedented steps, real GDP has "barely grown, an annual rate of 1\%" for several years. For Japan, the 1990s appear as a long and nearly uninterrupted period of recession. ${ }^{1}$

At the end of the 1980s, it would have been nearly impossible to envision such a predicament for this advanced industrialized nation. The Japanese economy enjoyed real growth of about $4 \%$ during that decade. Japan also managed to maintain near price stability during the 1980s. Starting with the collapse of equity prices at the end of the 1980s, however, a number of structural problems have emerged during the 1990s and as a result the Japanese economy is still going through a process of adjustment. ${ }^{2}$ Although the Bank of Japan eventually adopted a policy of zero overnight nominal interest rates, the deflationary environment that persisted through much of the 1990s placed a lower bound on the short-term real rate of interest and ruled out the negative real interest rates that the Bank might have chosen to promote, had inflation been higher. Thus, the earlier success of maintaining an environment of near price stability may have contributed, at least to some degree, to the

\footnotetext{
${ }^{1}$ While the slow growth in real GDP may be partly due to slow growth in potential output, available estimates still suggest a significant negative output gap. For example, the June 1999 OECD Economic Outlook estimated output gaps of $2.5 \%$ and $4.3 \%$ respectively for 1998 and 1999 .

${ }^{2}$ The Bank's perspective on these developments has been articulated on several occasions, e.g. by Governor Hayami (1999), and Deputy Governor Yamaguchi, (1999a,b). Recent analyses of the economic conditions in the Japanese economy appear in Aghevli, Bayoumi and Meredith (1998) and International Monetary Fund (1999).
} 
difficulties in providing sufficiently expansionary monetary conditions to ease the economy out of its slump.

At least for the past thirty years, the question of whether the zero bound on nominal interest might present such a practical difficulty for the conduct of monetary policy did not appear to be an important issue. The primary concern of monetary policy in most industrialized countries was how to reduce inflation, and achieve and maintain price stability — not how to defend against the possible pitfalls associated with deflation. The success in achieving the price stability goal and the lessons offered by the recent experience in Japan, however, have again focused attention on the zero bound. An example of this confluence of events and concerns became evident at a 1996 central bank conference sponsored by the Federal Reserve Bank of Kansas City in Jackson Hole, Wyoming. The topic of the conference, "Achieving Price Stability," was meant to describe policies for reducing inflation but the issues associated with the deflationary environment in Japan also became part of the discussion. As IMF First Deputy Managing Director Fischer noted: "On Japan, I don't doubt that Japanese monetary authorities would have liked to have cut the real interest rate, if they could have, and that the zero constraint on the nominal rate did have an impact on the speed or lack of speed with which they are coming out of the recession" (1996, p. 50).

Largely in response to these developments, a number of studies have recently started to investigate the theoretical and practical relevance of the zero bound. Among these studies, Krugman (1998), Wolman (1998) and McCallum (1999) have examined the analytical underpinnings of the zero bound and the liquidity trap in different models. From a quantitative perspective, the deterioration in stabilization performance due to the zero bound has been evaluated in estimated models of the U.S. economy by Fuhrer and Madigan (1997), Orphanides and Wieland (1998) and Reifschneider and Williams (1999). Buiter and Panigirtzoglou (1999) and Goodfriend (1999) have addressed theoretical and implementationoriented questions regarding the possibility of circumventing the zero bound by imposing a tax on currency and reserve holdings. Clouse, Henderson, Orphanides, Small and Tinsley 
(1999), Johnson, Small and Tryon (1999) and Small and Clouse (1999) have studied the role of policy options other than traditional open market operations as well as potential legal constraints on Federal Reserve policy actions that might be contemplated to ameliorate difficulties from the presence of the bound.

In this paper, we address a question that has not yet been adequately examined in this literature, namely the optimal design of monetary policy in the presence of the zero bound on nominal interest rates. Although the zero bound introduces a structural nonlinearity in any macroeconomic model, so far, quantitative analyses have focussed on evaluating its effect under simple Taylor-type policy rules for setting the nominal interest rate with alternative inflation or price level targets. ${ }^{3}$ Here, we use numerical dynamic programming methods to compute the optimal policy, which may be nonlinear, and contrast the solution to that obtained when the zero bound is ignored.

For this purpose, we use a simple calibrated open-economy model, which incorporates both an interest and exchange rate channel of monetary policy transmission. At first, we analyze the optimal policy in this model without the zero bound. Once we introduce the zero bound into the model, we also allow the quantity of base money to have some direct effect on aggregate demand and inflation, even when the nominal interest rate is constrained at zero. The particular channel for such quantity effects that we focus on is the portfolio balance effect. This effect implies that the exchange rate will respond to changes in the relative domestic and foreign money supplies even when interest rates remain constant at zero. We show that in the presence of such quantity effects it is important to discuss the policy stance in terms of base money, whenever nominal interest rates are constrained at zero. Of course, empirical estimates of such effects based on data from periods where interest rates were unconstrained are very imprecise. We account for parameter uncertainty regarding such quantity effects as well as for uncertainty due to price and demand shocks explicitly in our analysis. Our findings indicate that uncertainty about the continued effectiveness of policy has important consequences for understanding the behavior of the economy near

\footnotetext{
${ }^{3}$ Most of the studies use linear rules with constant coefficients. Reifschneider and Williams (1999) found that time-varying intercept adjustments to such a rule can ameliorate the impact of the zero bound.
} 
price stability and the costs associated with the zero bound. We find that the optimal policy near price stability is asymmetric, that is, as inflation declines policy turns expansionary sooner and more aggressively than would be optimal in the absence of the zero bound. We also show that the same asymmetry arises when the direct quantity effects are known with certainty but large variations in the quantity of money cannot be executed costlessly. As a consequence of the optimal policy, the average level of inflation is biased upwards. This bias arises, because policymakers are faced with a tradeoff between the level of inflation and economic stabilization performance when the economy is operating near the zero bound.

The paper is organized in six sections. Following the introduction, in section 2, we offer a brief discussion of the zero bound issue in theory and in practice, drawing from the recent Japanese experience and the U.S. experience in the 1930s. In section 3 we introduce our simple model abstracting both from the zero bound and from the existence of direct quantity effects. In section 4 we then examine optimal policies incorporating the constraint as well as small uncertain quantity effects. In section 5 we relate our analysis to some operational issues regarding the communication and implementation of policy at the zero bound given the recent experience in Japan. Section 6 concludes.

\section{The zero bound}

Questions regarding the role of the zero bound on nominal interest rates as a possible impediment on the effectiveness of monetary policy for countering slumps are not new. The origins of these questions can be traced to discussions of the "liquidity trap" following Keynes (1930, 1936), and Hicks (1937). A large literature followed, especially in the 1950s and 1960s and many elements of more recent discussions are closely related to this earlier debate. $^{4}$

The issue of the zero bound is simple to describe. The bound arises because market participants can avoid negative interest rates by holding money instead of interest-bearing assets. From a theoretical perspective, whether the interest rate can be pushed to zero, to a

\footnotetext{
${ }^{4}$ See Brunner and Meltzer (1968) and the references therein.
} 
small positive or to a small negative number depends on the specification of preferences and role of money in the economy. (See McCallum, 1999 and Woodford, 1999.) As a practical matter, the recent experience in Japan as well as evidence from the Great Depression suggest that the zero bound is a concrete possibility.

Under normal circumstances, when the short-term interest rate is well above the zero bound, a central bank can ease monetary policy by expanding the supply of the monetary base and bringing down the short-term rate of interest. Since prices of goods and services are slower to adjust than those on financial instruments, such a money injection reduces real interest rates (at least over short maturities) providing a stimulus to the economy. Depending on how long the liquidity injection is expected to persist and on the transmission of monetary policy to income and prices, real interest rates at longer maturities can be reduced in this way as well. The presence of the zero bound places a limit on this mechanism. In principle, the central bank can inject enough liquidity in the economy so as to push the overnight rate effectively to zero. Beyond that point, additional increases in the monetary base no longer noticeably affect short-term nominal interest rates. Real interest rates may even increase in the event of deflationary pressures. Thus, to the extent that the interest rate channel is the primary channel through which monetary policy operates, the presence of the zero bound can present a serious impediment to the policy process.

Figures 1 and 2 illustrate this point using recent data for Japan and interwar data for the United States. In each figure, the vertical axis shows the short-term nominal interest rate (in percent). The horizontal axis shows the supply of the monetary base as a ratio of nominal income, the Marshallian K (in percent). As can be seen from figure 1, the Federal Reserve increased the Marshallian K during most of the 1930s, but increases after 1934 could hardly be reflected in the rate of interest. Similarly, from Figure 2, the Marshallian $\mathrm{K}$ in Japan has increased quite noticeably since 1996 while the short interest rate hardly registers a change since that year. Figure 1 also shows how the Federal Reserve failed to raise the monetary base sufficiently to keep up with income in 1934, inducing a reduction in the Marshallian K that year. In the following years the Marshallian K increased to nearly 
16 percent in 1939, a quantity of money-per-unit-income more than twice as high as the level prevailing before the Great Depression. By comparison, as Figure 2 shows, the Bank of Japan has expanded the supply of money-per-unit-income more consistently in the past few years.

These figures also bring to attention two other aspects of monetary policy associated with the zero bound which we will address in greater detail later in this study. First, once monetary policy successfully pushes the short-term nominal interest rate to zero, it may become quite important to specify in greater detail how the monetary transmission mechanism may operate through channels other than changes in the short-term rate of interest and the associated influence of these changes on the term-structure of interest rates. When the normal variation of the Marshallian $\mathrm{K}$ is one or two percentage points, as was the case in the United States during the 1920s, it is unlikely that the effect of a 5 percentage point increase such as seen between 1934 to 1939 is adequately summarized by the corresponding reduction in the short-rate of a few basis points. While econometric models that are estimated or calibrated using data from normal periods when the economy operates safely away from the zero bound can provide useful estimates of monetary transmission through the interest rate channel, they are unlikely to capture the quantity effects that remain operative when nominal interest rates are constrained at zero with much precision. As a result, it is very difficult to produce exact quantitative comparisons of the relative stance of monetary policy during such episodes. Furthermore, once the short-term interest rate becomes effectively zero, it is not helpful to gauge the extent of further monetary expansion by merely referring to the short-term rate of interest. Rather, under these circumstances, it is worthwhile to pay closer attention to the quantity of the monetary base.

As mentioned before, these issues are not novel. McCallum (1990) argued that the Great Depression might have been prevented had policy followed a monetary base rule. In the context of the situation in Japan, a number of economists had suggested that the Bank of Japan place additional emphasis on the monetary base and perhaps consider quantitative objectives such as maintaining the growth of the monetary base to implement and communi- 
cate policy even before the Bank's adoption of the "zero interest rate policy." Goodfriend's (1997) remarks at a 1995 Bank of Japan conference provided an early thoughtful analysis explaining the role of a quantitative monetary expansion. At the same conference, Taylor (1997) pointed out that the deflation in Japan "made an interest rate rule unreliable, calling for greater emphasis on money supply rules" (p. 36). Friedman (1997), Hayashi (1998), and Meltzer (1998) provide more recent statements along these lines. As figure 2 indicates, the Bank of Japan, has consistently increased the monetary base faster than the growth of nominal income in recent years. Whether a faster or slower rate of growth might have been preferable then or should be adopted now remains a difficult and open question. In what follows we investigate some of the reasons for this difficulty.

\section{The model without a zero bound and quantity effects}

\subsection{An open economy}

As the starting point of our analysis we employ a simple open economy model with an interest and exchange rate channel, but abstracting from the zero bound and direct effects of the quantity of money. The model is an extension of the closed economy model we used earlier in Orphanides (1998) and Orphanides and Wieland (1999) and shares many features

with the open economy models presented in Ball (1999) and Svensson (1999). The model has a very simple lag structure. This is necessary to render the numerical computation of optimal policies under uncertainty in the presence of the zero bound tractable. For this reason it is best interpreted as an annual model. In earlier work on the effect of the zero bound under linear Taylor-type interest rate rules in Orphanides and Wieland (1998) we used a more realistic estimated quarterly model which was fitted to U.S. data for the 1980s and 1990s. However, given the large number of state variables in such a model, computation of the optimal nonlinear policy by means of dynamic programming techniques would not be feasible.

The key variables in this model are the inflation rate $\pi$, measured as the log difference in prices, the output gap $y$, measured as the deviation of the log of real output from its full 
employment trend, the log of the real exchange rate $x$ (a higher $x$ denotes an appreciation), the short-term real interest rate $r$ and the short-term nominal interest rate, $f$. For $f$ we have in mind a rate such as the federal funds rate in the U.S. or the uncollateralized overnight call rate in Japan. The four key behavioral equations are an open-economy Phillips curve, an open-economy aggregate demand equation, an equation determining the reduced-form relationship between the real interest rate and the real exchange rate, and a Fisher equation relating the nominal and real interest rate:

$$
\begin{gathered}
\pi_{t+1}=\phi E_{t} \pi_{t+1}+(1-\phi) \pi_{t}+\alpha y_{t+1}-\gamma\left(x_{t}-x_{t-1}\right)+\epsilon_{t+1} \\
y_{t+1}=\rho y_{t}-\xi\left(r_{t}-r^{*}\right)-\chi\left(x_{t}-x^{*}\right)+\eta_{t+1} \\
x_{t}-x^{*}=\theta\left(r_{t}-r^{*}\right)+\nu_{t} \\
r_{t} \equiv f_{t}-E_{t} \pi_{t+1}
\end{gathered}
$$

We use the superscript ${ }^{*}$ to denote the long-run deterministic equilibrium levels of corresponding variables. So $r^{*}$ is the equilibrium real interest rate and $x^{*}$ the equilibrium real exchange rate. The corresponding equilibrium for the output gap is by definition equal to zero. All parameters are positive.

The open economy Phillips curve (1) allows for partially forward looking price setting with the parameter $\phi \in(0,1)$ serving as a bridge between a limiting case corresponding to the Lucas supply function $(\phi=1)$ with rational expectations and one corresponding to the accelerationist Phillips curve $(\phi=0)$. The lagged inflation term may either be motivated by backward-looking expectations or by contracting-type rigidities similar to Fuhrer and Moore (1995). ${ }^{5}$ The change in the exchange rate affects inflation through import prices. Equation (2) describes the dynamics of aggregate demand. The autoregressive component captures the persistence that characterizes cyclical movements in output in the data. In addition, both the real interest rate and real exchange rate influence aggregate demand. The two

\footnotetext{
${ }^{5}$ Optimal monetary policy with a closed-economy version of this Phillips curve was recently analyzed in detail by Clark, Goodhart and Huang (1999). The empirical evidence regarding the role of backward- and forward-looking expectations and structural rigidities is provided by Roberts (1997).
} 
shocks $\eta$ and $\epsilon$ capture aggregate demand and aggregate supply or inflation disturbances and are the source of the cyclical fluctuations in the model. We assume they are drawn from zero mean independent normal distributions.

In a closed economy, equations (1) and (2) would form the core of the determination of inflation and output dynamics. In the open economy, an additional equation is necessary to capture the link between the real interest and real exchange rate. Following Ball (1999), we adopt the specification in equation (3) to highlight in a simple fashion the fact that under normal circumstances a reduction in the short-term interest rate leads to a depreciation of the currency. $\nu_{t}$ captures other influences on the exchange rate such as changes in foreign interest rates, possible changes in perceptions regarding the equilibrium exchange rate level and other factors. We treat this as exogenous to the model and largely abstract from its treatment. In simple versions of the Mundell-Fleming-Dornbusch model of exchange rate dynamics, equation (3) directly follows from the uncovered interest rate parity condition and $\theta$ is determined by the speed of adjustment of the real exchange rate to its long-run level. ${ }^{6}$ This result does not hold exactly in our model. However, we retain equation (3) as our benchmark because it greatly simplifies the solution of the model in the presence of non-linearities such as the zero bound on nominal interest rates we introduce below. ${ }^{7}$

Equation (4) defines the real interest rate in terms of the fed funds rate (the shortterm nominal rate) and expected inflation. Treating the fed funds rate as the operating instrument of the central bank, these four equations would complete the description of the economy, even though what the central bank ultimately controls operationally is the monetary base. Under normal circumstances, it is quite appropriate to treat the federal funds rate as the policy instrument as explained for instance by Bernanke and Blinder (1992) for the United States, and Ueda $(1993,1997)$ for Japan.

\footnotetext{
${ }^{6}$ For example, with a mean lag of one year, $\theta=2$. See Dornbusch (1986), part I for details.

${ }^{7}$ Abstracting from the zero bound, it is straightforward to show that the features of the model are essentially the same if equation (3) is replaced with the uncovered interest rate parity condition. We assume that this remains to be the case once we introduce the zero bound non-linearity in the model.
} 


\subsection{Policy preferences}

We endow the policymaker with symmetric preferences that are quadratic in the deviation of inflation, $\pi$, from a desired target, $\pi^{*}$, and the output deviation from the economy's natural output level, $y$. The per-period loss facing a policymaker in period $t+1, l_{t+1}$, can therefore be expressed as a weighted average of these two components:

$$
l_{t+1}=\omega\left(\pi_{t+1}-\pi^{*}\right)^{2}+(1-\omega) y_{t+1}^{2}
$$

Furthermore, we assume that the policymaker discounts the future with a fixed discount factor $\beta$. As is clear from the timing structure of the model, monetary policy operates with a one period lag. Thus, during period $t$, policy is geared towards stabilizing the economy from period $t+1$ forward. As a result, we can view the policymaker's objective in period $t$ as to minimize the expected discounted sum of future per-period losses from $t+1$ onward:

$$
\mathcal{L}_{t}=E_{t}\left\{\sum_{s=0}^{\infty} \beta^{s} l_{t+1+s}\right\}
$$

The policymaker solves this problem subject to the dynamic structure of the economy as described by equations (1)-(5). Next, we provide a brief outline of the solution. ${ }^{8}$

\subsection{Solution}

The flow of information in the model proceeds as follows. At the beginning of each period $t$, the values of the aggregate demand and supply shocks, $\eta_{t}$ and $\epsilon_{t}$ and foreign exchange market pressures, $\nu_{t}$, are realized. Note from equations (1) and (2) that with the realizations of $\eta_{t}$ and $\epsilon_{t}, \pi_{t}$ and $y_{t}$ are also observed at the beginning of the period. The policymaker sets policy for the period by setting the fed funds rate, $f_{t}$, in response to the realizations of these state variables. Contemporaneously, market participants form expectations regarding inflation in period $t+1, E_{t} \pi_{t+1}$, based on the observable state variables, and an assessment of the current policy action in response to the current state. Market expectations together

\footnotetext{
${ }^{8}$ More detailed treatments of the necessary steps appear in the Ball (1999), Svensson (1999), Orphanides and Wieland (1999) and Clark, Goodhart and Huang (1999) papers cited earlier. Since these steps are fairly standard in the linear-quadratic case, we only provide highlights below. The numerical algorithm we employ to solve the model once we deviate from the linear-quadratic case is described in the appendix of the ECB working paper version of Orphanides and Wieland (1999).
} 
with the policy action determine the current levels of the real interest and real exchange rate. Of course, in setting the fed funds rate, the policymakers take into account the influence of their action on market expectations, the real interest rate and the real exchange rate.

Note that due to the simple structure of the model the relevant expectations, $E_{t} \pi_{t+1}$ can be formed without an assessment of future policy actions, i.e. $f_{t+1}$. As a result, in the rational expectations equilibrium of the baseline version of our model without the zero bound, $E_{t} \pi_{t+1}$ can be expressed as a linear function of the four state variables, $\pi_{t}, y_{t}, x_{t-1}$ and $\nu_{t}$, and the current policy, which is also a linear function of those same state variables.

In solving the model, it is useful to recognize that the joint influence of current inflation and currency depreciation on future inflation can be summarized with a single variable. This variable, which we denote by $\tilde{\pi}_{t}$, can be interpreted as the underlying rate of inflationary pressures which would obtain if the central bank maintained output at its potential. It is defined as:

$$
\tilde{\pi}_{t} \equiv \pi_{t}+\frac{\gamma}{1-\phi}\left(x_{t-1}-x^{*}\right)
$$

We refer to this measure as the underlying rate of inflation. Its steady state is the same as that of the actual inflation rate, $\tilde{\pi}^{*}=\pi^{*}$. To see why this redefinition simplifies the model observe that equation (1) can be rewritten in terms of $\tilde{\pi}$ as:

$$
\tilde{\pi}_{t+1}=\phi E_{t} \tilde{\pi}_{t+1}+(1-\phi) \tilde{\pi}_{t}+\alpha y_{t+1}+\epsilon_{t+1}
$$

This shows that $x_{t-1}$ only influences the dynamics of the system through its effect on $\tilde{\pi}_{t}$.

With these transformations, the dynamics of the system can be described in terms of just three variables, $\tilde{\pi}_{t}, y_{t}$ and $\nu_{t}$. Since the foreign exchange market pressures, $\nu_{t}$, is an exogenous variable in our model and is not central for our discussions, we simplify the problem further by setting it equal to zero at all times.

Given these assumptions, the linear-quadratic nature of the problem implies a simple representation of the optimal policy, which takes a form similar to Taylor's rule:

$$
f_{t}-f^{*}=a_{\pi}\left(\tilde{\pi}_{t}-\pi^{*}\right)+a_{y} y_{t}
$$


Here $f^{*} \equiv \pi^{*}+r^{*}$, and the optimal response parameters $a_{\pi}$ and $a_{y}$ are functions of the underlying model parameters, $\alpha, \gamma, \theta, \xi \rho, \phi$ and $\chi$, and the policymaker preference parameters, $\omega$ and $\beta$. Similarly, since all financial variables in the model are determined simultaneously, this solution could be written in terms of the real interest rate or real exchange rate.

$$
\begin{aligned}
& r_{t}-r^{*}=b_{\pi}\left(\tilde{\pi}_{t}-\pi^{*}\right)+b_{y} y_{t} \\
& x_{t}-x^{*}=c_{\pi}\left(\tilde{\pi}_{t}-\pi^{*}\right)+c_{y} y_{t}
\end{aligned}
$$

There exists a unique correspondence between the optimal response coefficients in the fed funds policy rule, $a_{\pi}$ and $a_{y}$, and the response coefficients in the other two rules. which involves the parameters of the underlying model economy.

\subsection{Money}

Although we can abstract completely from the introduction of money in the model as specified above, the instrument that the central bank uses remains the monetary base. Since the model in equations (1)-(4) does not allow for any direct role of money in the economy, it is sufficient to treat monetary policy as if the central bank controls the federal funds rate directly, leaving the relationship between the monetary base and the federal funds rate in the background. However, since this relationship will become more important once we introduce the zero bound on nominal interest rates, it is useful to introduce it explicitly at this point. Perhaps the simplest way to do so is to posit a linear relationship between money-per-unit-income and the nominal rate of interest. ${ }^{9}$ Thus, let $k$ denote the log of the Marshallian $\mathrm{K}$ for the monetary base and $k^{*}$ the corresponding steady state level that would obtain if the economy were to settle down to a deterministic steady state inflation $\pi^{*}$. Then, a baseline formulation of the demand for money (ignoring the zero bound) is

\footnotetext{
${ }^{9}$ The convenient assumption of a simple linear relationship between the rate of interest and the Marshallian $\mathrm{K}$ (or its inverse, the velocity of money) is quite common in formulations of money demand specifications and widely used. An early example at the Federal Reserve is the original specification of money demand in the MPS model (Modigliani, Rasche and Cooper (1970)). A recent example is Orphanides and Porter (1998). An implicit restriction of such a specification is that of a unit income elasticity on money demand. Quarterly money demand models typically add short-run adjustment dynamics around the static linear relation, but we abstract from these adjustment dynamics here.
} 
simply:

$$
f_{t}-f^{*}=-\delta\left(k_{t}-k^{*}\right)+\mu_{t}
$$

The relationship implied by equation (11) is also apparent from Figures 1 and 2, if one restricts attention to normal circumstances when the interest rate is not near zero. The Japanese data from 1970 to 1995, for instance, suggests that reducing the Marshallian K by one percentage point, would be associated with a change in the short-term nominal rate of interest of about four percentage points. To allow for a simple translation of policies when stated in terms of interest rates and in terms of the Marshallian K, in what follows we set $\delta=1.0$, implicitly normalizing the definition of $k$. With this normalization, raising the fed funds by one percentage point is equivalent to reducing $k$ by one percentage point, under normal circumstances. Alternatively - and this is the convention we will retain for the remainder of the paper-whenever we refer to changing $k$ by one percentage point, we will imply a change in the Marshallian K by as much as would be necessary to effect a one percentage point change in the short-term interest rate, under normal circumstances.

A useful way to interpret equation (11) is as a simple description of the money market that determines the quantity of high-powered money that the central bank needs to supply to achieve a desired level for the federal funds rate. Reducing the supply of money-perunit-income, $k$, raises the federal funds rate. Assuming that the central bank observes contemporaneous income, we can treat money-per-unit-output, $k$, as the effective policy instrument. $\mu_{t}$, summarizes other influences to the demand for money, in addition to changes in interest rates or income. This term includes short-run shocks to money demand but also reflects changes in the transactions or payments technology or in preferences that may have long-lasting and even permanent effects on the level of Marshallian $\mathrm{K}$ consistent with the steady state inflation, $\pi^{*}$. Regardless of its determinants, since the central bank controls $k_{t}$ and can easily observe the federal funds rate, $f_{t}, \mu_{t}$ is essentially observable to the central bank. That is, fixing $k_{t}$, even a slight movement in the federal funds rate can be immediately recognized as a change in $\mu_{t}$ and, if desired, immediately counteracted. Thus, using equation (11) we can express the optimal policy setting (8) in terms of the monetary 
base.

$$
k_{t}-k^{*}=-a_{\pi}\left(\tilde{\pi}_{t}-\pi^{*}\right)-a_{y} y_{t}+\mu_{t}
$$

Equation (12) illustrates both that the optimal policy can be expressed in terms of the quantity of money but also that doing so would require active management of the supply of money to counteract not only economic fluctuations as reflected in the movements of inflation and output but also additional factors influencing the demand for money that are unrelated to inflation and output. It is exactly the presence of these additional influences that encourages the treatment of the interest rate as the central bank's operating instrument. And, these additional influences may well induce occasional appearances of instability in the relationship between the monetary base, economic activity and inflation. In practice, the problem becomes even more complex once we recognize that income is not observed contemporaneously. This implies that $\mu_{t}$ is only partially observed, and that as a result, policymakers must tackle a complex filtering problem as highlighted by Poole's (1970) influential work on this issue.

\subsection{A parametric example}

We consider the following parameters for the model, which are chosen to be roughly realistic for a large open economy such as the United States or Japan with annual data.

For the Phillips curve we set $\phi=0.5, \alpha=0.25, \gamma=0.05$. The value for $\phi$, is motivated by reduced form equations for inflation such as estimated by Fuhrer and Moore (1995) and Roberts (1997). Based on this, we set $\alpha=(1-\phi) / 2.0$ to reflect a sacrifice ratio of two in the model which is in the range of point estimates suggested by studies for various countries including the U.S. and Japan. For the output equation we set $\xi=0.3$ and $\chi=0.03$. We illustrate the effect of output persistence by initially setting $\rho=0.5$ but then simplify the model further by setting $\rho=0$, as we explain below. The low values for $\gamma$ in the inflation equation and $\chi$ in the output equation reflect our emphasis on a large-open economy. For a small open economy, these two parameters should be set at substantially larger values. Finally, for the exchange rate equation we set $\theta=2.0$, the parameter setting suggested by 
Ball (1999). With these parameters, an unexpected increase in the fed funds rate by 100 basis points results in a reduction of 0.6 percent of output by the end of the following year. A 10 percent appreciation of the currency results in a corresponding reduction of nearly 1 percent. As a baseline setting for preferences, we assume that the policymaker places equal weight on output and inflation stabilization, that is $\omega=0.5$, and uses a discount factor $\beta$ of 0.9 .

With these parameters, and abstracting from the zero bound, the optimal policy can be readily determined. As is well known, in this case the policy is a linear function of inflation deviations from target and of the output gap, with response coefficients, $a_{\pi}$ and $a_{y}$ in equation (8), which are independent of the choice of inflation target, $\pi^{*}$, and the value of the equilibrium real interest rate $r^{*}$, and are not influenced by the variances of the underlying structural disturbances in the economy, $\eta$ and $\epsilon$. With these assumptions, the optimal policy stated in terms of the interest rate is:

$$
f_{t}=r^{*}+\pi^{*}+2.1\left(\tilde{\pi}_{t}-\pi^{*}\right)+0.9 y_{t}
$$

And, of course, the corresponding policy stated in terms of the Marshallian $\mathrm{K}$ is simply:

$$
k_{t}=k^{*}-2.1\left(\tilde{\pi}_{t}-\pi^{*}\right)-0.9 y_{t}+\mu_{t}
$$

Later on, when we introduce the zero bound, the optimal policy response will be nonlinear and will depend the specific values chosen for the inflation target and the equilibrium real rate. At that point we will set $\pi^{*}=1$ and $r^{*}=2$ as a benchmark for analysis.

Another characteristic of the model is that the optimal responsiveness of the optimal rule to the underlying inflation rate, $a_{\pi}$, is independent of the autoregressive term in the output equation, $\rho{ }^{10}$ The role of $\rho$ is limited to determining the optimal responsiveness to the output gap with greater persistence requiring more vigorous response. Thus, if $\rho=0.8$ the optimal response becomes $a_{y}=1.5$. If $\rho=0$ the optimal response is also $a_{y}=0$. In each case, the optimal response to inflation remains unchanged.

\footnotetext{
${ }^{10}$ This aspect of the model is discussed in more detail in Orphanides and Wieland (1999).
} 
Consequently, we can simplify our numerical analysis further by setting $\rho=0$ which eliminates the need to keep track of the evolution of the output gap for discussing the setting of optimal policy. Although, this implies a loss of realism in terms of interpreting the behavior of output in the model, little is lost for discussing either the behavior of inflation or the optimal policy response to inflation. On the other hand, eliminating the need to keep track of lagged output results in a major simplification in the numerical solution of the problem once we introduce the zero bound on interest. Thus, in what follows, we retain the setting $\rho=0$.

\section{Introducing the zero bound and direct quantity effects}

\subsection{Negative interest rates and the liquidity trap}

From a practical perspective, the analysis in the previous section offers a useful, though stylized summary of how a central bank might formulate and implement monetary policy when the zero bound is not of concern, that is when inflation is fairly high. In a low inflation environment, however, it is incomplete as long as the zero bound is not incorporated directly into the analysis. Consider, for instance the equations describing the optimal setting of policy, (13) and (14) with $\pi^{*}=0$ and $r^{*}=1$. If a shock to aggregate demand or inflation creates a temporary deflation bringing inflation down to say $\pi_{t}=-1 \%$, the optimal response of the central bank is to raise the money supply so that $k_{t}$ is raised by 2.1 percentage points (after counteracting any disturbances reflected in $\mu_{t}$ ). But, from equation (13), doing so would require a negative setting of the federal funds rate for the period. This prescription violates the zero bound and does not represent a feasible policy option.

To examine policy in the presence of the zero bound, we modify our simple representation of the demand for money, and recognize explicitly that beyond some level, once the shortterm rate is pushed to its floor, additional expansions of the monetary base no longer influence the short-term rate of interest. A simple modified version of money demand can then be written as follows:

$$
f_{t}=\left[r^{*}+\pi^{*}-\delta\left(k_{t}-k^{*}\right)+\mu_{t}\right]_{+}
$$


where []$_{+}$truncates the quantity inside the brackets at zero. Returning to Figures 1 and 2, this effectively maintains a downward linear relationship between the Marshallian $\mathrm{K}$ and the nominal interest rate as long as the rate is positive, but then traces the horizontal axis for greater values of $k$.

This modification, however, exposes an additional limitation of the model. As written, the model comprising of equations (1)-(4) and (15) is globally unstable. Once shocks to aggregate demand and/or supply push the economy into a sufficiently deep deflation, the zero bound in equation (15) shuts off the only channel of the monetary transmission mechanism present in the model rendering monetary policy completely ineffective. Worse, by maintaining expectations of continuing deflation, a zero interest rate policy may not suffice for keeping the real interest rate below its equilibrium level. With a shock large enough to keep the short-term real interest rate above its equilibrium level, aggregate demand is suppressed further sending the economy into a deflationary spiral. In our earlier work on the zero bound, (Orphanides and Wieland (1998)), we resolved this global instability problem by assuming that at some point, in a depression-like situation, fiscal policy would turn sufficiently expansionary to rescue the economy from such a deflationary spiral. Here, we concentrate instead on the role of other channels of the monetary transmission mechanism that may continue to operate even when the interest rate channel is ineffective.

\subsection{Quantity effects}

Mishkin (1995) offers a very useful overview of the alternative channels of the monetary transmission mechanism and Calomiris (1993) examines the role of non-interest rate channels of monetary policy during the Great Depression. A number of studies have emphasized the credit channel as deserving special attention. This channel is reviewed by Bernanke and Gertler (1995). Since a reduction in interest rates is typically the easiest way to bring about an ease of credit conditions, identifying this effect under normal circumstances is not an easy task. But some evidence does point towards the importance of this channel even after controlling for interest rate movements. For Japan, Hoshi, Scharfstein and Singleton 
(1993) find support for a direct loan availability effect in the form of "window guidance." In the United States, Kashyap, Stein and Wilcox (1993) offer evidence for the independent effect of credit conditions as measured by outside risk spreads on economic activity.

In an open economy, another important element of the monetary transmission mechanism is the determination of the exchange rate. To the extent that a monetary easing induces a depreciation of the currency, it can effectively counteract a deflation, both, because of the direct effect of the exchange rate on prices and because of the expansionary impact of an improvement in net exports on aggregate demand. Again, under normal circumstances, a reduction in interest rates is typically the easiest way to achieve a depreciation of the currency and the model we specified in the previous section does incorporate this interest-rate-induced exchange rate effect. However, it may also be possible to achieve a depreciation via monetary expansion, even when the short-term interest rate is constrained to remain at the zero floor. Monetary models of the determination of the exchange rate, such as reviewed in Frankel and Mussa (1985), suggest that the current level of the exchange rate is influenced by the expected relative future supplies of domestic and foreign nominal money balances. Thus an increase in domestic money balances that is understood to be sustained will influence the current exchange rate even if it cannot be reflected in current short-term interest rates. ${ }^{11}$ As with the credit channel for the monetary transmission mechanism, empirical confirmation of this effect and estimates of its magnitude are quite difficult to obtain. An attempt to do so is presented by Dominguez and Frankel (1993) who identify a small but statistically significant effect of Fed and Bundesbank foreign exchange interventions on the level of the exchange rate during the late 1980s.

Monetarist models have always emphasized the special role of the quantity of money

\footnotetext{
${ }^{11}$ There is an important asymmetry in this argument, which is highly relevant in the context of the zero bound. It may be quite difficult for a government to engineer and maintain an appreciation of a currency since this may entail sales of possibly limited foreign reserve holdings and may have adverse consequences on government finances which may not be sustainable over a long period. On the other hand, a depreciation of a currency - if desired - can always be enforced by purchases of foreign assets financed by additional printing of domestic currency. There is no limit to the depreciation of a currency that can be achieved by the authority that controls the printing press. This is not to imply that uncontrolled money creation would be a prudent action but merely to point out that there is no inherent constraint on policies directed towards depreciating a currency.
} 
in the economy. Friedman and Schwartz (1963) offer a classic interpretation of U.S. monetary history with this perspective. Meltzer (1995) attributes this role to imperfect substitutability between alternative financial assets. As he explains, because of this imperfect substitutability, changing the quantity of money has direct effects on the prices of these assets, including prices on long-term bonds. Meltzer (1999) emphasizes the importance of examining these aspects of the transmission mechanism in the context of the liquidity trap. If a quantitative expansion of the monetary base raises the real value of financial wealth-regardless of the mechanism - then such an expansion will have a positive impact on aggregate demand, even if the short-term interest rate is at the zero bound. This mechanism can also be seen as a restatement of the real-balance effect in Pigou (1943).

The imperfect substitutability of alternative assets, of course, is also an integral part of Keynesian models of the economy. Tobin (1958), provided an early theoretical analysis of the Keynesian liquidity preference schedule in a framework that integrated investment decisions of risky alternatives such as as long-term bonds. In this framework, a change in the quantity of money would continue to influence asset prices regardless of whether the overnight interest rate remains at zero. As Keynes (1930) himself emphasized, monetary policy could influence the rate of investment and prices with expansionary monetary policy by reducing the cost of financing new investment which, of course, depends on long-term interest rates and external financing spreads, not just the overnight interest rate. And while he contemplated the limiting factors on policy that relate to the zero bound on nominal interest rates, he concluded: "[t]hus, I see small reason to doubt that the Central Bank can produce a large effect on the cost of raising new resources for long-term investment, if it is prepared to persist with its open-market policy far enough." (p. 372)

It is difficult to find direct evidence of the effects of an increase in the quantity of the monetary base on alternative assets when the overnight nominal interest rate is essentially zero. In a recent study, however, Hanes (1999) presents some important evidence that bears directly on this issue drawing on the behavior of the U.S. money market during the 1930s. Hanes examines the effect of weekly changes in the supply of reserves on various interest 
rates from 1934 to 1939, a period during which the overnight rates were effectively equal to zero and an ample degree of liquidity supplied by the Federal Reserve created the credible expectation that the overnight rates would remain at zero, at least over a short horizon. He presents evidence that positive shocks in the supply of reserves lowered treasury bill rates and yields on 3-5 year Treasury notes during that period even though these interest rates were already quite low. This finding suggests that an expansion in the quantity of money can reduce the term-premium on risk-free securities thereby influencing longerthan-overnight short-term and perhaps intermediate-term interest rates even when the zero bound maintains the overnight interest rate at the floor and when additional injections of liquidity may not influence expectations of the overnight rates in the near future.

In summary, examination of these alternative monetary transmission channels suggests that some direct effects of the quantity of money on the economy can be added to our baseline model. While such effects are likely be quantitatively unimportant relative to the interest rate channel under normal circumstances, they will play a central role once the interest rate channel may be rendered ineffective by the zero bound.

A simple way to introduce these quantity effects is by modifying the output and exchange rate equations in the model to allow for a direct effect of $k$.

$$
\begin{gathered}
y_{t+1}=\rho y_{t}-\xi\left(r_{t}-r^{*}\right)-\chi\left(x_{t}-x^{*}\right)+\lambda\left(k_{t}-k^{*}\right)+\eta_{t+1} \\
x_{t}-x^{*}=\theta\left(r_{t}-r^{*}\right)-\kappa\left(k_{t}-k^{*}\right)+\nu_{t}
\end{gathered}
$$

Setting either $\lambda$ or $\kappa$ to positive values, serves to recognize that additional channels of the monetary transmission mechanism continue to operate at the zero bound. The values of these parameters relative to $\xi$ and $\theta$, can be used to indicate the significance of these secondary channels relative to the interest rate channel under normal circumstances. Either one of these two terms, however small it is, will be sufficient to render the baseline version of our model globally stable in the presence of the zero bound.

We illustrate the role of these quantity effects with an example where we maintain $\lambda$ at zero, set $\kappa$ to 0.2 and leave all other parameters as before. This choice of parameter 
values implies that the quantity effect of a monetary ease on the exchange rate is an order of magnitude smaller than the interest rate effect. In the absence of the zero bound, this modification has only a tiny effect on the optimal policy rule. In our example, the optimal response to inflation changes from $a_{\pi}=2.1$ when $\kappa=0.0$ to $a_{\pi}=2.0$ when $\kappa=0.2$.

Because of its small magnitude and the fact that under normal circumstances the indirect effect of money injections on the exchange rate through interest rates would dominate movements in the exchange rates, it would not be surprising for econometric estimation to fail to detect its presence. The same would be true regarding the introduction of a small quantity effect in the output equation, e.g. $\lambda>0$. A lesson from this example is that if the direct effects of the quantity of money are small or - as a practical matter -if their quantitative significance is approximated sufficiently well by estimating a model that lumps such effects together with the role of interest rates, little is lost under normal circumstances. The estimated optimal policies could well be nearly identical, whether the direct influence of the quantity of money is properly accounted for by the model or not.

\subsection{The role of quantity effects with the zero bound}

Once the zero bound renders the interest rate channel ineffective, the non-interest rate channels become of crucial importance for policy. In fact, if these quantity channels were well understood and their quantitative effects on aggregate demand and inflation accurately measured, monetary policy could rely on them to circumvent the ineffectiveness of the interest rate channel. To see this, it is sufficient to consider the solution to a counterfactual example, which assumes that the interest rate channel is inoperative at all times, by setting the parameters $\xi$ and $\theta$ equal to zero, but maintaining $\kappa$ at 0.2 as in the example above. Now the money demand and real interest rate equations of the system become irrelevant and the only transmission mechanism is the small quantity-of-money effect on the exchange rate. The model is still linear so we can easily determine the optimal policy response to an inflation gap as before. The optimal policy again involves setting the money supply deviation from its deterministic steady state $k_{t}-k^{*}$ as a linear function of the underlying 
inflation rate gap, $\tilde{\pi}_{t}-\pi^{*}$. But since the quantity-of-money effect is very weak, the policy multiplier is considerably higher than 2.0 in this case. Indeed, with $\kappa=0.2$ the optimal responsiveness of $k$ to inflation in our example is about 50! Of course, this response may appear unreasonably high and is not to be taken literally. It simply reflects the assumption that the only operational channel of the transmission mechanism is very weak. If the only operative channel of the monetary transmission mechanism under the zero bound makes a money injection an order of magnitude weaker than normal, then the appropriate degree of money injection in response to a deflationary shock is an order of magnitude bigger. Of course, this is the case only if the quantity effect of such a large money injection is known with certainty. In actual practice, these effects are at best estimated with very little precision. We will assess the impact of uncertainty below.

As far as the welfare costs of this strategy are concerned, the size of the response remains irrelevant as long as the multiplier of the direct quantity effect is known with certainty and the large variation in the quantity of money which is implied by this strategy can be implemented at no cost. Also, because of the simplicity of our model, the policies defined above in terms of $k$ are for all practical purposes sufficient to characterize the optimal decision in the case when the interest rate effect is present in the model but possibly inoperative because of the zero bound. In this case, the optimal solution essentially puts together the two different segments of the optimal policy response depending on whether the zero bound is in effect or not. If inflation is high so that the optimal policy is not influenced by the existence of the zero bound, the optimal responsiveness to inflation at the margin is 2.0. If inflation is so low that the interest rate channel is inoperative, the optimal responsiveness to inflation at the margin is about 50. This illustrates that the optimal policy in the presence of quantity effects that are known with certainty entails a rather abrupt change in focus from small changes in the fed funds rate under normal conditions to possibly large changes in the quantity of the monetary base when the bound is in effect.

We need to emphasize, however, that arriving at an exact policy prescription which quantifies the responsiveness of monetary policy under the zero bound is extremely difficult. 
While we can easily enumerate a number of secondary channels of the monetary transmission mechanism which suggest that expansion of the monetary base can have some expansionary effect on the economy, the quantitative magnitude of any such effect may be very small and is certainly highly uncertain.

\subsection{Uncertainty regarding the effectiveness of policy}

The empirical relevance of the quantity effects discussed in the previous section has been much debated, primarily because the available estimates, which are based on data from normal periods, are very imprecise at best. Thus, in investigating the optimal policy in the presence of the zero bound, it is crucial to account for the substantial degree of uncertainty regarding the magnitude of such quantity effects. When considering a rapid monetary expansion to counteract deflationary pressure, a policymaker would need to take into account concerns that with some probability this policy may result in a rate of inflation much higher than desired. In practice, this concern appears to have been a significant consideration for the setting of policy in Japan during 1999. A member of the BOJ Monetary Policy Committee, Kazuo Ueda, offered this analysis regarding the wisdom of a very rapid monetary base expansion designed to end deflationary concerns and quickly achieve a moderate inflation:

"How about a policy of letting the monetary base grow at 20 or $30 \%$ then? Inflation does not seem to be on the horizon. One can tighten after the inflation rate reaches 1 or $2 \%$. We think such a policy would have a small chance of success for reasons already mentioned. When it does succeed, it will probably generate a much higher inflation rate than 1 or $2 \%$. Because of lags in the effects of policy, the $20-30 \%$ money growth will continue to generate inflationary pressure even after the tightening starts." (July 6, 1999.)

As implied in this quotation, uncertainty regarding the effectiveness of a monetary expansion concerns both, the overall effectiveness of the expansion over time as well as its lag structure. Since the lag structure in our model is collapsed into just one period, we also need to collapse the dynamic multiplier uncertainty to the one period when the effect of the monetary expansion affects the economy as well. To do so we introduce uncertainty regarding the policy multiplier $\kappa$ following Brainard's (1967) treatment of multiplier uncertainty. Specifically, we assume that $\kappa$ is stochastic and is drawn from a normal distribution with 
mean 0.2 as before but with a positive standard error to reflect the multiplier uncertainty. In illustrating the effect of such parameter uncertainty, we assume that $\kappa$ is drawn from a normal distribution with a standard error of 0.4. Furthermore, we set the standard deviations of the demand and price shocks $\eta$ and $\epsilon$ to 1.0 percent and the money demand shock, $\mu_{t}$, to zero.

It is useful to first examine the consequences of parameter uncertainty for the optimal policy in the absence of the zero bound. Recall that the optimal responsiveness of $k$ and $f$ to a marginal change in inflation without the multiplier uncertainty is about 2.0. Because the direct quantity effect in the absence of the bound is very small, uncertainty regarding this effect hardly changes the optimal policy in this case. The optimal response coefficient drops by less than 0.1 and continues to equal 2.0 after rounding to one decimal.

While the effect of uncertainty regarding $\kappa$ is essentially negligible under normal conditions, its presence looms large under the zero bound. Figure 3 compares the optimal setting of $k$ when $\kappa$ is known with certainty to the case where it is only estimated very imprecisely. Figure 4 shows the corresponding optimal setting of the federal funds rate. In both figures, the solid lines show the optimal responses incorporating all sources of uncertainty in the model while the dotted lines show the deterministic segments corresponding to the policy that ignores the zero bound (with a slope of about 2) and the counterfactual policy that ignores the interest rate channel of the transmission mechanism (with a slope of about 50) discussed in the previous sections. All policies are computed under the assumptions that the target rate of inflation in the policymaker's loss function, $\pi^{*}$, equals 1 percent and the real equilibrium interest rate $r^{*}$ equals 2 percent.

Two important characteristics of the optimal policy are evident in these figures. First, as can be seen in Figure 3, if the economy does enter a deflation, the policymaker expands the monetary base quite aggressively but still much less so than would be suggested by a policy that ignored the uncertainty about the quantity effect on the exchange rate and the associated risk of higher and more variable inflation. 
Second, concerns about the presence of the bound distort the optimal setting of policy even at positive rates of inflation where the bound would not ordinarily be a constraining factor. The presence of the zero bound makes policy increasingly more responsive to inflation as inflation falls. To show this more clearly, Figure 5 plots the marginal responsiveness of the interest rate. In the absence of the bound, the marginal responsiveness would have been constant and equal to 2.0 regardless of the level of inflation. With the bound, a responsiveness of 2.0 only obtains (asymptotically) when inflation is very high. For lower inflation rates, however, policy responsiveness increases as inflation falls until the zero bound is encountered. From this point on, the interest rate remains at zero and no longer provides information about the optimal policy stance. Note also that with our baseline parameter settings, the zero bound is encountered as soon as inflation has fallen about half a percentage point below the policymaker's target of one percent.

The rationale for this response is simple. A forward looking policymaker properly recognizes the costs of implementing policy under the zero bound and takes precautionary measures to reduce the probability of deflation, thereby reducing the probability of encountering the difficulties associated with stabilization policy in a deflationary environment. This tendency is still very much apparent at the target inflation rate of one percent. The corresponding optimal federal funds rate setting is more than one percentage below the equilibrium nominal rate of 3 percent. Clearly, such a policy will introduce a bias in the level of inflation compared to the target $\pi^{*}$. This bias arises, because the policymaker is faced with a tradeoff between the level of inflation and economic stabilization performance when the economy is operating near the zero bound.

\subsection{Concerns regarding monetization of debt}

Uncertainty regarding the magnitude of quantity effects is not the only relevant concern

when the central bank is constrained by the zero bound and contemplates unusually large injections of money into the economy. Another practical and possibly very important question is whether the central bank can execute such large changes in the quantity of money 
in circulation without incurring any costs. Although raising the quantity of money by purchases of government debt may not present a problem, exercising the huge volume of sales of government debt that would be required to quickly reverse this action in the future may present one. The issue is a pesky political economy complication. To the extent that the government is not expected to raise future taxes to finance money creation but is expected to do so to repay private holdings of government debt, heavy issuance of new money may create some pressure for monetization of some of the debt bought by the central bank with the new issues. ${ }^{12}$ The end result could be substantial inflation.

Whether this problem is a significant concern or not clearly depends on the institutional framework governing the central bank, the underlying political environment and the state of government finances. As a practical matter, this issue appeared to be of concern for the Bank of Japan during 1999. Although the issue was typically discussed in the context of outright purchases of long-term government debt, it would be of concern regardless of the maturity of the underlying instrument that the Bank purchases to inject new liquidity in the economy. Bank of Japan Governor Hayami voiced this concern in a speech delivered on March 18, as follows:

"[I]t is totally unacceptable for a central bank to adopt measures that could lead to unlimited financing of the fiscal deficit or ones that could be interpreted as such... Even though there is no need at the moment to consider the risk of inflation, we cannot rule out the possibility of some kind of a 'demand shock' occurring over the longer term... To contain such inflationary pressure, it would be necessary to drastically tighten monetary policy. As a result, the economy would be forced to go through severe adjustments.

The risk of inflation causing a wide swing of the economy can only materialize in the distant future, but the Bank of Japan, being responsible for maintaining price stability, must always be fully alert to such a risk. It is this strong commitment to maintaining price stability over time that makes monetary policy that could lead to the loss of fiscal discipline unacceptable."

Although our model is too simple to capture the political economy aspects of such concerns it offers an indirect way to address them. Essentially, the concern raised above

\footnotetext{
${ }^{12}$ This also emphasizes a more general complication, which we have abstracted from so far, namely the behavior of the fiscal authority and the possible limitations constraining the government's authority, power, or political consensus for debt finance. See e.g. Sims (1994) for an analysis of the intricate interactions between fiscal and monetary policy that arise once this issue is examined more closely.
} 
makes it costly for the central bank to raise the Marshallian $\mathrm{K}$ very fast and/or very much because of the potential difficulty in reducing it in subsequent periods when sales of possibly large quantities of government paper would be necessary in order to achieve this reduction. To capture such concerns, we can introduce another element in the loss function, which penalizes very large deviations in $k$ from its deterministic steady state, as follows:

$$
l_{t+1}=\omega\left(\pi_{t+1}-\pi^{*}\right)^{2}+(1-\omega) y_{t+1}^{2}+\tau\left(k_{t}-k^{*}\right)^{2}
$$

For simplicity, we model the cost as symmetric but note that we could as easily introduce an asymmetric cost, e.g. $\tau\left(\left[k_{t}-k^{*}\right]_{+}\right)^{2}$. Introducing an asymmetry in the loss function is largely unnecessary, because the presence of the zero bound already generates such an asymmetry. The reason is the following. The Marshallian $k$ need not vary by much under normal circumstances when small changes in $k$ can influence interest rates. Thus, introducing this element in the loss function with a small weight $\tau$ (e.g. $\tau=0.01$ ) hardly matters under normal circumstances. However, at the zero bound, when the marginal effect of providing additional liquidity in the economy is small, these considerations gain additional force and become quantitatively important when $k$ needs to be large to counteract deflationary concerns.

The effect of introducing such a penalty in the loss function is qualitatively quite similar to the role of uncertainty regarding the effectiveness of the quantity effect in the monetary transmission mechanism. In the absence of the zero bound, setting $\tau$ to a small positive constant rather than zero has negligible effects on policy. With the zero bound, it distorts the optimal setting of $k$ in similar ways as uncertainty regarding $\kappa$. Figure 6 compares the baseline case with uncertainty about $\kappa$ to alternative policies without such uncertainty, but with values of $\tau$ of 0.01 and 0.05 (dashed lines). (The solid and dash-dot lines are as described in Figures 3 to 5 . As can be seen from the middle and the bottom panel, of Figure 6 for $\tau=0.01$ the distortion in the setting of the federal funds rate is very close to the distortion induced in the case of an uncertain $\kappa$ with a standard error of 0.4 . 


\subsection{The inflation level and variability tradeoff}

In earlier work on the zero bound when policy is set according to Taylor-type interest rate rules in an empirically estimated quarterly model with rich dynamics (see Orphanides and Wieland (1998)), we found that the distortions introduced by the zero bound depend in a nonlinear fashion on the level of the inflation target and largely disappear once the target is set at a high enough value. In that paper we also identified a tradeoff between the average level and the variability of inflation. Here we revisit this question in the context of optimal policies under alternative targets in the more stylized, calibrated model of this paper.

Figure 7 shows the optimal policies when the inflation target $\pi^{*}$ equals 1 percent (solid line), -2 percent and 3 percent (dashed lines) respectively. The value of -2 percent is of interest in the context of Friedman's rule. In a world without the zero bound, the target of -2 percent would exactly offset the equilibrium real interest rate of $2 \%$, and result in an average nominal interest rate of zero percent. Of course, once the zero bound is recognized, this outcome is not achievable any more. As can be seen from the middle panel, the optimal policy with a target of $-2 \%$ implies that the federal funds rate is lowered to zero as soon as inflation has fallen to about zero percent, that is, long before the target rate of $-2 \%$ is achieved. Thus, as the inflation target is lowered, the nonlinearity of the optimal policy becomes more pronounced. Alternatively, if we raise the inflation target to 3 percent, the nonlinearities are somewhat attenuated. For example, as can be seen from the middle and the bottom panels, if inflation is on target then the federal funds rate is set at about $5 \%$ which corresponds to the steady state level that would obtain without the zero bound, and the policy responsiveness to inflation is very close to 2.0 , as in the case without the zero bound.

As we discussed in our earlier paper, the presence of the zero bound may induce a tradeoff between the average level of inflation relative to the policymaker's target $\pi^{*}$ and the variability of inflation. Furthermore, as shown in the preceding analysis the precautionary motive of a forward looking policy maker will tend to make policy counteract incipient deflationary pressures much more forcefully than incipient inflationary pressures, which 
introduces in bias in the optimal policy. An implication of this bias is that inflation, on average, will exceed the policymaker's deterministic target, $\pi^{*}$, which is equal to the average that would obtain in the absence of the zero bound. In addition, despite the efforts to avert deflation, when deflation does occur and the effectiveness of monetary policy becomes more uncertain, stabilization of the economy becomes more difficult. Thus, the variability of inflation will also be greater than would obtain in the absence of the zero bound.

\subsection{Sensitivity analysis}

In the presence of the zero-bound the optimal policy no longer exhibits the certaintyequivalence properties which characterize the optimal policy in a linear world without the bound. Furthermore, the optimal policy responsiveness to inflation is no longer independent of the level of the inflation target, the equilibrium real interest rate and the degree of uncertainty. To gauge the sensitivity of our numerical results to these parameters, we have computed solutions to the nonlinear optimization problem for alternative choices of those parameter settings.

In Figure 8 we examine the effect of alternative degrees of parameter uncertainty about $\kappa$, that is, uncertainty about the pure quantity effects of policy. We compare the baseline standard error of $\kappa$ of 0.4 to solutions with values of 0.3 and 0.5 (dashed lines). As shown in the upper panel, the degree of caution regarding large injections of liquidity when interest rates are constrained at zero increases with the degree of parameter uncertainty. As shown in the middle and lower panels, the precautionary interest rate response prior to hitting zero is more pronounced the higher is the degree of parameter uncertainty.

Figure 9 shows the optimal policies for alternative degrees of uncertainty due to price and demand shocks, $\epsilon$ and $\eta$. We consider values for the respective standard errors, of 0.5 , 1.0 and 1.5. As expected, we find that the nonlinearities in the optimal policy show up more strongly, the higher is the variance of the shocks. For example, the middle panel of Figure 9 indicates that with respective standard errors of 1.5, the optimal policy setting when inflation equals the target rate of 1 percent, is a federal funds rate of zero percent. 
Finally, we consider the impact of alternative values of the equilibrium real interest rate on the optimal policy. As shown in Figure 10, the higher the real equilibrium the smaller the nonlinearities induced by the possibility of hitting the zero bound. If the equilibrium real rate equals $3 \%$ the optimal funds rate setting when inflation is on target, is only slightly below $4 \%$ which would be the equilibrium level in a world without the zero bound.

\section{Operational Issues}

We now turn from the model-based analysis to some more operational issues, in particular, questions regarding the communication of the policy stance near the zero bound and their relevance to the recent Japanese experience. Under normal circumstances, monetary policy can be communicated and implemented by "setting" the overnight nominal interest rate. Depending on the operating procedures this may involve exact pegging of the interest rate but need not be exact. Pegging requires the willingness for continuous monitoring and intervention in the federal funds market which may be unnecessary for the conduct of monetary policy. For instance, with current operating procedures, under normal circumstances the Federal Reserve undertakes an open market operation just once a day, in early morning. This permits intra-day fluctuations in the fed funds rate. Though these fluctuations imply that the rate is not exactly at the intended level at all times, its average over longer periods such as a month or a quarter rarely deviates from the intended level by an amount that would be meaningful or even noticeable for the performance of the economy.

It is still possible to communicate the policy stance near the zero bound by setting the overnight nominal interest rate, as long as that rate remains positive. Once it is pushed to zero, however, communication of the stance of policy becomes more complex. Consider, for instance, the Bank of Japan's guidelines for money market operations following the February 12, 1999 decision to push the overnight interest rate towards zero, the "zero interest rate policy." The key sentence is: ${ }^{13}$

\footnotetext{
${ }^{13}$ This is taken from the announcement following the October 27, 1999 meeting. This or a nearly identical sentence has appeared in all announcements since February 12, 1999.
} 
"The Bank of Japan will flexibly provide ample funds and encourage the uncollateralized overnight call rate to move as low as possible."

To be sure, the adoption of this policy unambiguously represented a significant easing of monetary conditions. At the zero bound, however, this information may not fully convey the degree of monetary easing that is intended. One question is the exact interpretation of the phrase "as low as possible". The Bank of Japan has interpreted "as low as possible" to be equal to about three basis points, the level believed to be the lowest one at which the overnight market would continue to operate smoothly. In other words, the lowest level at which transaction costs and the slim risk spread in the uncollateralized market are covered and a positive volume of transactions in this overnight market is maintained. ${ }^{14}$

Should the monetary policy committee decide that additional easing is warranted in view of incoming data, additional room is available. For instance, the same policy could be re-interpreted as one that attempts to push the overnight interest rate literally to zero. The existence of a transaction/risk cost of even a few basis points, of course, would imply that the overnight market would largely disappear and transactions at a zero overnight rate might not be observed. Instead, some overnight transactions could be replaced with transactions of successively longer term contracts, such as one-week, four-week or longer terms. Thus, implementing a policy that literally pushes the overnight rate to zero might require sufficient injection of liquidity to drive the interest rate "as low as possible" on shortterm instruments with longer maturities. Such additional injections of liquidity would shave a few additional basis points off these longer-than-overnight short-term interest rates and perhaps also off longer maturities across the term structure spectrum. ${ }^{15}$

This example indicates why communicating policy in terms of the overnight interest rate may not always be sufficient to describe the stance of monetary policy as that rate is pushed towards zero. At that point it also becomes useful to consider the value of alternatives that

\footnotetext{
${ }^{14}$ The volume in the uncollateralized call money market has fallen sharply following the February easing and is closely watched by the BOJ in this regard. (See e.g. Okina, 1999, footnote 11.) It is interesting to note that a similar drop in the volume of money market borrowing was experienced in the U.S. as short-term rates approached zero in the early 1930s (Hanes, 1999).

${ }^{15}$ Indeed, the evidence presented by Hanes (1999), drawing from the U.S. experience during the 1930s suggests that the yields of even multi-year treasury securities might drop by a few basis points.
} 
might convey additional information regarding the intended policy stance. One possibility is to focus on the quantity of money. For instance, the central bank could communicate its policy by providing a short-term "target" for the monetary base Marshallian K, or, perhaps, the growth of the monetary base estimated to be consistent with the desired "target." To give an example, the central bank might determine that 10 percent growth in the monetary base is appropriate based on current economic conditions in an environment where any base growth beyond e.g. 5 percent would result in a "zero" overnight rate. Surely, unexpected changes in the demand for currency or the reserve market (the term $\mu_{t}$ in our model) would imply that the central bank might not want to literally "target" the monetary base. Furthermore, the central bank would wish to accommodate high-frequency fluctuations in the demand for high powered money that are deemed unrelated to macroeconomic conditions as it does when the zero bound is not in effect. ${ }^{16}$

Another possibility is to resort to the exchange rate as a means for communicating and implementing policy. This strategy, which has been recently examined by McCallum (1999) in the zero-bound context, would require that the central bank attempt to set the nominal exchange rate in response to economic conditions. However, much like the base, the exchange rate is subject to a number of influences in addition to domestic macroeconomic developments that the central bank would not ordinarily wish to accommodate (the term $\nu_{t}$ in our model). And depending on the exact institutional setting governing the relationship between the central bank and the fiscal authorities, pegging the exchange rate may require additional changes in the normal operating procedures of the central bank.

In essence, the disadvantages associated with implementing monetary policy through quantitative targets or the exchange rate under normal circumstances are still present when the overnight rate is pushed to zero. Thus, it may be preferable to communicate and implement policy using longer-than-overnight interest rates when the overnight rate is effectively

\footnotetext{
${ }^{16}$ An additional difficulty with the zero bound, however, is that the information regarding such shocks that under normal circumstances would automatically be reflected in the overnight interest rate is lost. This information loss makes adjustment of quantitative targets more difficult. The markets would still provide information in movements of rates at somewhat longer maturities but interpreting the quantity of liquidity that might be necessary to offset a movement of e.g. 1 basis point under these conditions might be subject to large errors.
} 
pushed to zero. For instance, the central bank may expand or contract monetary policy by varying the term of instruments it adopts as targets for pushing the interest rate "as low as possible." Indeed, in the case of the Bank of Japan, only a slight modification from its current directive would be required if additional monetary easing were deemed necessary. This would simply replace "uncollateralized overnight call" with a different short term instrument, for instance "N-week repo" where the number of weeks, N, would increase as necessary e.g. from two to thirteen weeks to reflect progressively greater monetary easing, as needed.

From an operational perspective, this method of communicating the policy stance at the zero bound essentially retains the same mode of operation as what is in place under normal circumstances. A closely related alternative is to switch to a policy of targeting the rate of a short-term instrument with sufficiently long maturity whose rate need not be zero at the time the policy is adopted (e.g. six months.)

It is interesting to note in this respect, that the choice of the overnight rate as an operating instrument is not the universally preferred mode of operation among central banks even under normal conditions. Unlike the Federal Reserve and the Bank of Japan, for instance, the Bank of England uses the two-week repo rate as its operating instrument. Although under normal circumstances the two may appear nearly identical, the difference between bringing a two-week rate "as low as possible" compared to bringing an overnight rate "as low as possible" may be considerable.

Regardless of the way in which the central bank opts to communicate and implement a quantitative easing, the direction of expected movements in the exchange rate, short interest rate term premia and the quantity of money will be similar. In every case, the central bank controls the quantity of high powered money. The approaches differ to the extent that this supply is adjusted to offset shocks to the domestic or foreign demand for money. Abstracting from such shocks, implementing a quantitative expansion by raising the Marshallian $\mathrm{K}$ of the monetary base will be associated with a depreciation of the currency and a (perhaps only slight) drop in term premia on longer-than-overnight short-term interest rates. Since 
these three alternatives are in essence just alternative ways of looking at the same policy, it may be advantageous for the central bank to utilize all three to communicate its policy intentions. This may be particularly useful if the perceptions of policy intentions in the market are ambiguous.

As a hypothetical example, consider that the Bank of Japan decided to provide additional monetary stimulus to the economy given the current conditions. To be specific, suppose that the Bank of Japan believes that this stimulus would be consistent with a projected monetary base growth of about 10 percent, a yen/dollar exchange rate of around 120 and a reduction in the one-month interest rates by two basis points. ${ }^{17}$ From an operational perspective, the Bank of Japan could communicate its intention in terms of all three concepts. The policy directive could be stated in terms of the intent of reducing the one-month interest rate but at the same time the Bank could explicitly state that its actions are taken with the expectation that the exchange rate consistent with this policy would be 120 and with the expectation that this policy is projected to result in a growth of the monetary base by about 10 percent.

Of course, shocks to the demand for the monetary base might well require accommodation so the actual monetary base growth will likely vary from the announced projection. Likewise, an unexpected increase in the demand for yen in the foreign exchange markets might require greater than anticipated injections of yen in the economy in order to maintain the exchange rate from appreciating beyond the projected value of 120 . With short interest rates near zero, neither of these shocks would be reflected in overnight interest rates but both would influence the exchange rate unless actively counteracted. Since it might be difficult to verify the Bank of Japan's intent to counteract such shocks with the limited information from movements in the short interest rate, it may be beneficial to make these projections explicit and intervene in the market to supply as much high-powered money as would be necessary to counteract these developments. As a result, market participants

\footnotetext{
${ }^{17}$ These numbers are selected strictly as an illustration for our hypothetical example. The monetary base has been growing at about 5 percent during 1999. The exchange rate has appreciated by nearly 15 percent since mid-year to a current (November 1999) level of about 105 yen per dollar.
} 
would expect that any shocks which might exert pressure on the exchange rate, would be swiftly dealt with, thereby eliminating any possible market misperceptions regarding the Bank of Japan's policy. At the same time, it would remain entirely clear that the Bank does not target either the growth of the monetary base or the exchange rate and that the projected levels of either would be expected to change with changes in the outlook of economic activity and inflation as is the case under normal conditions.

\section{Conclusion}

While the zero bound on nominal interest rates shuts off the primary channel of monetary policy transmission, it need not imply that monetary policy becomes completely ineffective. Rather, other channels, which allow for direct quantity effects and may normally not be very relevant due to their small and uncertain magnitude, become important for stabilization policy. These additional channels range from the influence of monetary expansions on the level of the exchange rate, term spreads, outside risk spreads on financing instruments, asset revaluation and possible Pigouvian real-wealth effects.

In this paper, we have investigated optimal monetary policy near price stability allowing for the possibility of small pure quantity effects and explicitly incorporating uncertainty about these effects into the analysis. Since these channels are much weaker than the direct interest rate channel, substantially greater changes in the quantity of money, as measured by the Marshallian K, for instance, are required to bring about a desired increase on aggregate demand and inflation when the overnight interest rate is bound at zero. If the policy multipliers and the monetary transmission mechanism from these were well understood, the zero bound would not present a significant concern for stabilization policy. Policy would need to be much more activist in terms of the monetary base but could still effectively stabilize the economy. However, once uncertainty regarding these effects is taken into account the costs of successful stabilization policy near price stability increase substantially. Although the liquidity trap does not render monetary policy completely ineffective, its presence remains costly. 
The optimal policy in the presence of the zero bound exhibits two complementary elements that ameliorate the potential for deflationary crises. First, to mitigate the costs induced by the zero bound, it is optimal to respond asymmetrically to inflation. As inflation declines, policy turns expansionary sooner and more aggressively than would be optimal in the absence of the zero bound. Second, the optimal policy introduces an upward bias in inflation and distorts the stochastic distributions of economic outcomes. Thus, if a policy maker would have opted for zero inflation as the long-run policy target, the optimal stabilization policy near price stability will lead to an average level of inflation exceeding zero. In essence, the presence of the zero bound generates a tradeoff between economic stabilization and average inflation.

While our work confirms that, on an analytical level, the quantity aspects of the transmission mechanism can play an important role in the presence of the zero bound, we also discuss how monetary policy may continue to use interest rate instruments on an operational level, if that is deemed more appropriate by the central bank. Because the stance of policy cannot be effectively communicated in terms of the overnight rate at the zero bound, the policy directive would eventually need to be suitably adjusted to longer-than-overnight short-term interest rates. 


\section{References}

Aghevli, Bijan B., Tamim Bayoumi and Guy Meredith (1998), Structural Change in Japan, International Monetary Fund, Washington, D.C.

Ball, Laurence (1999), "Policy Rules for Open Economies," in Taylor ed. (1999).

Bernanke, Ben and Alan Blinder (1992), "The Federal Funds Rate and the Channels of Monetary Transmission," American Economic Review, 57, 2, 411-25.

Bernanke, Ben and Mark Gertler (1995), "Inside the Black Box: The Credit Channel of Monetary Transmission," Journal of Economic Perspectives, 9(4) Fall, 27-48.

Brainard, William C. (1967), "Uncertainty and the Effectiveness of Policy," American Economic Review, 57, 2, 411-25.

Brunner, Karl and Allan Meltzer (1968), "Liquidity Traps for Money, Bank Credit, and Interest Rates," Journal of Political Economy, 76(1), 1-37, January/February.

Buiter, Willem H. and Nikolaos Panigirtzoglou (1999), "Liquidity Traps: How to Avoid Them and How to Escape Them," working paper, March.

Calomiris, Charles W. (1993), "Financial Factors in the Great Depression," Journal of Economic Perspectives, 7, 61-85, Spring.

Clark, Peter, Charles Goodhart and Haizou Huang (1999), "Optimal monetary policy rules in a rational expectations model of the Phillips curve", Journal of Monetary Economics, $43,497-520$.

Clouse, James, Dale Henderson, Athanasios Orphanides, David Small, and Peter Tinsley (1999), "Monetary Policy when the Nominal Short-Term Interest Rate is Zero," working paper, October.

Dominguez, Kathryn M. and Jeffrey A. Frankel (1993), "Does Foreign-Exchange Intervention Matter? The Portfolio Effect," American Economic Review, 83(5) 1356-1369, December.

Dornbusch, Rudiger (1986), Dollars, Debt, and Deficits, Cambridge, MA: MIT Press.

Fischer, Stanley (1996), "Why Are Central Banks Pursuing Long-Run Price Stability?" in Achieving Price Stability, Federal Reserve Bank of Kansas City.

Frankel, Jacob A. and Michael Mussa (1985), "Asset Markets, Exchange Rates and the Balance of Payments" in Jones and Kenen (1985).

Friedman, Milton (1997), "Rx for Japan: Back to the Future," Wall Street Journal, December 17.

Friedman, Milton and Anna Schwartz (1963), "A Monetary History of the United States, 1867-1960".

Fuhrer, Jeffrey and Brian Madigan (1997), "Monetary Policy when Interest Rates are 
Bounded at Zero," Review of Economics and Statistics, November.

Fuhrer, Jeffrey C. and George R. Moore (1995) "Inflation Persistence" Quarterly Journal of Economics 110(1), 127-59, February.

Goodfriend, Marvin (1997), "Comments on Japanese Monetary Policy, Rules or Discretion? A Reconsideration," in Kuroda (1997).

Goodfriend, Marvin (1999), "Overcoming the Zero Bound on Interest Rate Policy," working paper, October.

Hanes, Christopher (1999), "The Liquidity Trap, the Supply of Reserves and U.S. Interest Rates in the 1930s," Manuscript.

Hayami, Masaru (1999) "Recent Monetary and Economic Conditions in Japan," article excerpted and translated by the Bank of Japan from a speech given at the Research Institute of Japan in Tokyo, March 18.

Hayashi, Fumio (1998), "The Bank of Japan Should Set a Base Money Target," Nikkei Daily, December 29. (in Japanese.)

Hicks, John (1937). "Mr. Keynes and the 'Classics'," Econometrica, 5(2), April.

Hoshi, Takeo, David Scharfstein, and Kenneth J. Singleton (1993), "Japanese Corporate Investment and Bank oj Japan Guidance of Commercial Bank Lending," in Singleton (1993).

International Monetary Fund (1999), "Japan: Staff Report for the 1999 Article IV Consultation," IMF Staff Country Report No. 99/83, August.

Johnson, Karen, David Small and Ralph Tryon (1999) "Monetary Policy and Price Stability," Federal Reserve Board, International Finance Discussion Paper 1999-641, July.

Jones, Ronald W., and Peter B. Kenen, eds. (1985), Handbook of International Economics, Volume II, Amsterdam: North Holland.

Kashyap, Anil K., Jeremy C. Stein, and David W. Wilcox (1993), "Monetary Policy and Credit Conditions: Evidence from the Composition of External Finance," American Economic Review, 83, 78-98, March.

Keynes, John M., (1930), Treatise on Money, Volume 2. London: MacMillan.

Keynes, John M., (1936), The General Theory of Employment, Interest and Money. London: MacMillan.

Krugman, Paul (1998), "It's Baaack: Japan's Slump and the Return of the Liquidity Trap," Brookings Papers on Economic Activity, 2:1998, 137-187.

Kuroda, Iwao, ed. (1997), Towards More Effective Monetary Policy, New York: St Martin's Press.

McCallum, Bennett T. (1999), "Could a Monetary Base Rule Have Prevented the Great 
Depression?" Journal of Monetary Economics, 26, 3-26.

McCallum, Bennett T. (1999), "Theoretical Analysis Regarding a Zero Lower Bound on Nominal Interest Rates," working paper, September.

Meltzer, Allan, (1995), "Monetary, Credit and (Other) Transmission Processes: A Monetarist Perspective," Journal of Economic Perspectives, 9(4) Fall, 49-72.

Meltzer, Allan, (1998), "Time to Print Money," Financial Times, July 17.

Meltzer, Allan, (1999), "Monetary Policy at Zero Inflation," August.

Mishkin, Frederic (1995), "Symposium on the Monetary Transmission Mechanism," Journal of Economic Perspectives, 9(4) Fall, 3-10.

Modigliani, Franco, Robert Rasche, J. Philip Cooper (1970), "Central Bank Policy, the Money Supply, and the Short-Term Rate of Interest," Journal of Money, Credit and Banking, 2(2), 166-218, May.

Okina, Kunio (1999), "Monetary Policy Under Zero Inflation: A Response to Criticisms and Questions Regarding Monetary Policy," Bank of Japan, IMES Discussion Paper Series 99-E-20, July.

Orphanides, Athanasios (1998), "Monetary Policy Evaluation With Noisy Information," Finance and Economics Discussion Series, 1998-50, Federal Reserve Board, October.

Orphanides, Athanasios and Richard Porter (1998), "P-star Revisited: Money Based Inflation Forecasts with a Changing Equilibrium Velocity," Finance and Economics Discussion Series, 98-26, Board of Governors of the Federal Reserve System, May. (Forthcoming, Journal of Economics and Business.)

Orphanides, Athanasios, and Volker Wieland (1998), "Price Stability and Monetary Policy Effectiveness when Nominal Interest Rates are Bounded at Zero," Finance and Economics Discussion Series, 98-35, Board of Governors of the Federal Reserve System, June.

Orphanides, Athanasios and Volker Wieland (1999), "Inflation Zone Targeting," ECB Working Paper 99-08, October. (Forthcoming, European Economic Review.)

Pigou, A.C. (1943), "The Classical Stationary State," Economic Journal, 53(212) 343-351, December.

Poole, William (1970), "Optimal Choice of Monetary Policy Instrument in a Simple Stochastic Macro Model," Quarterly Journal of Economics, 84(2), 197-216, May.

Reifschneider, David, and John Williams (1999), "Three Lessons for Monetary Policy in a Low Inflation Era," FEDS 1999-44, August.

Roberts, John (1997), "Is Inflation Sticky?," Journal of Monetary Economics, 39, 173-196.

Rotemberg, Julio and Michael Woodford (1998), "An Optimization-Based Econometric Framework for the Evaluation of Monetary Policy: Expanded Version" NBER Technical 
Working Paper, 233, May.

Sims, Christopher A. (1994) "A Simple Model for Study of the Determination of the price Level and the Interaction of Monetary and Fiscal Policy," Economic Theory, 4, 381-399.

Singleton, Kenneth J., ed. (1993), Japanese Monetary Policy, Chicago: University of Chicago.

Svensson, Lars E. O. (1999), "Open Economy Inflation Targeting," Journal of International Economics, forthcoming.

Taylor, John B., "Policy Rules as a Means to Monetary Policy," in Kuroda (1997).

Taylor, John B., ed. (1999), Monetary Policy Rules, Chicago: University of Chicago.

Tobin, James (1958), "Liquidity Preference as Behavior Towards Risk," Review of Economic Studies 25(2), 65-86, February.

Ueda, Kazuo (1993), "A Compararive Perspective on Japanese Monetary Policy: Short-Run Monetary Control and the Transmission Mechanism," in Singleton (1993).

Ueda, Kazuo (1997), "Japanese Monetary Policy, Rules or Discretion? A Reconsideration," in Kuroda (1997).

Ueda, Kazuo (1999), "The Bank of Japan's Forward Looking Approach," Remarks at the Meeting on Economic and Financial Matters in Kagoshima, July 1.

Wieland, Volker (1998), "Monetary Policy under Uncertainty about the Natural Unemployment Rate," Finance and Economics Discussion Series, 98-22, Board of Governors of the Federal Reserve System.

Wolman, Alexander S. (1998), "Staggered Price Setting and the Zero Bound on Nominal Interest Rates," Federal Reserve Bank of Richmond Economic Review, 84, 1-24, Fall.

Woodford, Michael (1999), Interest and Prices Manuscript.

Yamaguchi, Yutaka (1999a), "Monetary Policy and Structural Policy: A Japan Perspective," Remarks prepared for a conference at the Banque de France, October 8-9, 1999.

Yamaguchi, Yutaka (1999b), "Asset Price and Monetary Policy," Remarks at a symposium sponsored by the Federal Reserve Bank of Kansas City in Jackson Hole, Wyoming, August 26-28, 1999. 
Figure 1

\section{Marshallian K and Short-Term Interest Rate United States: 1920-1939}

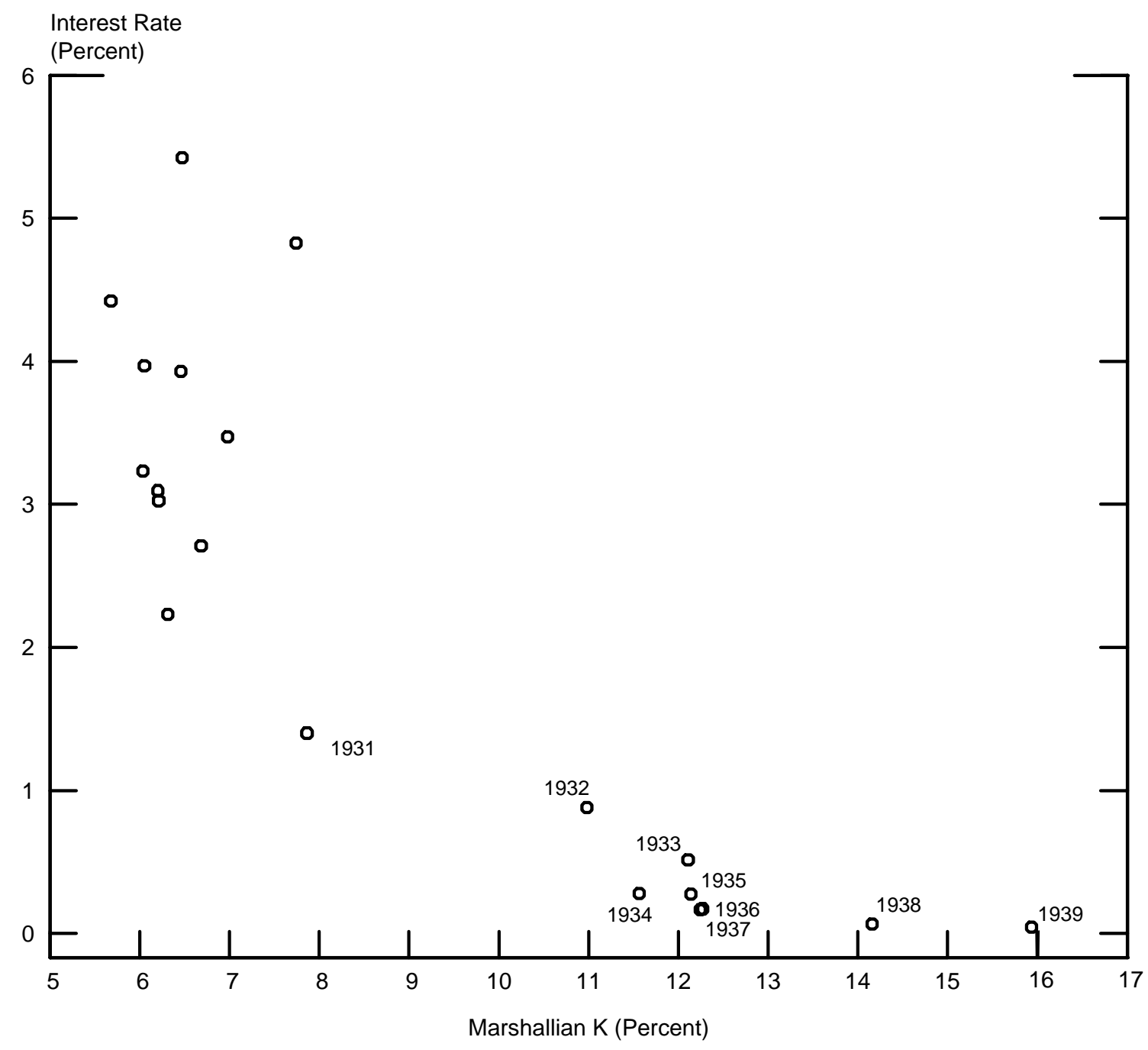

Notes: The Marshallian K is the ratio of the monetary base and nominal GNP. The interest rate reflects the yield on three-six month Treasury bills or Treasury notes and certificates of similar maturity from the NBER historical database. All data are annual averages of monthly or quarterly data, in percent. 
Figure 2

\section{Marshallian K and Short-Term Interest Rate Japan: 1980-1999}

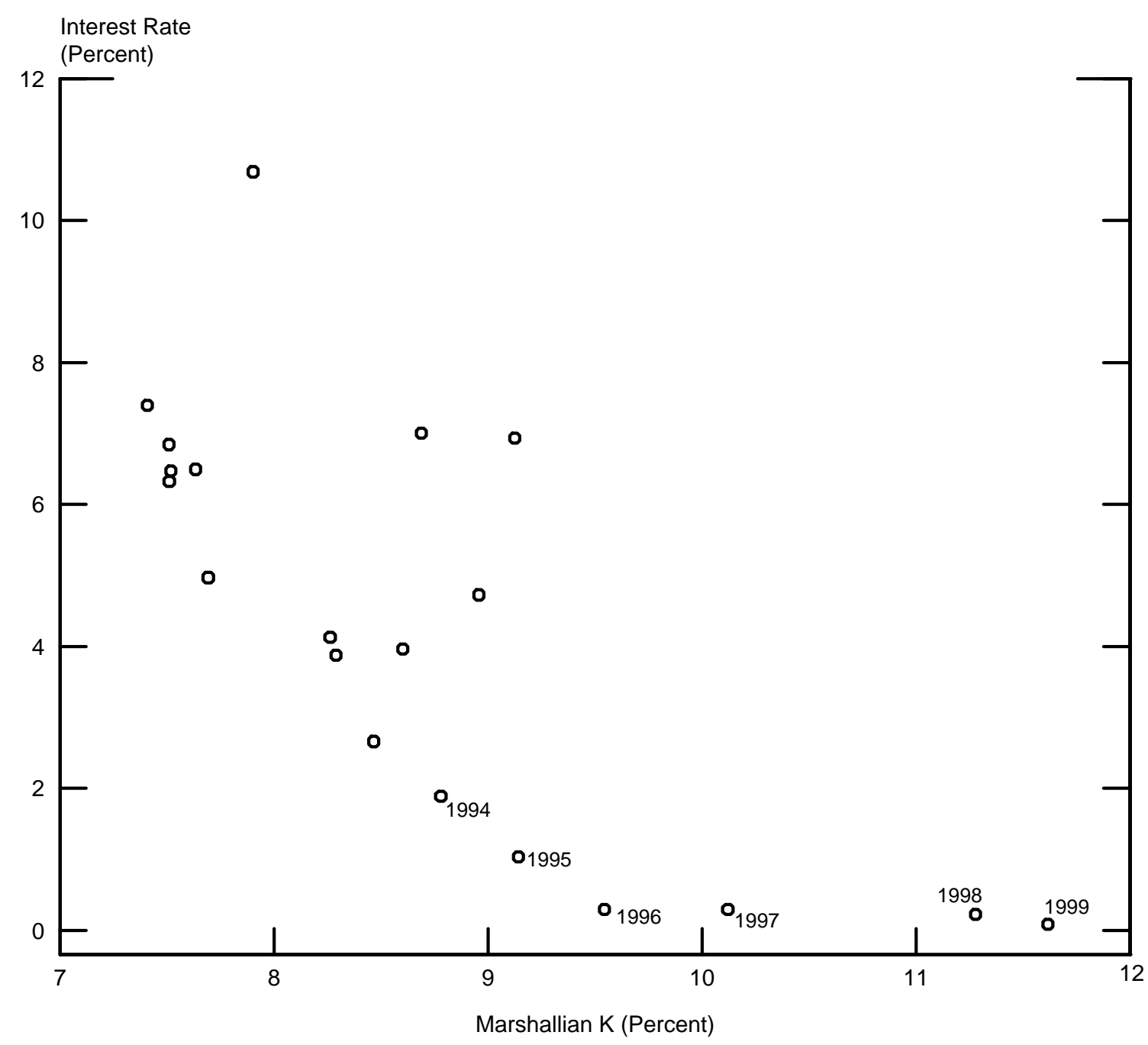

Notes: The Marshallian $\mathrm{K}$ is the ratio of the monetary base and nominal GDP. The interest rate reflects the three-month Gensaki rate. All data are annual averages of monthly or quarterly data, in percent. For 1999, the averages include data ending with Q2. 
Figure 3

\section{Optimal Policy for the Marshallian K Gap}

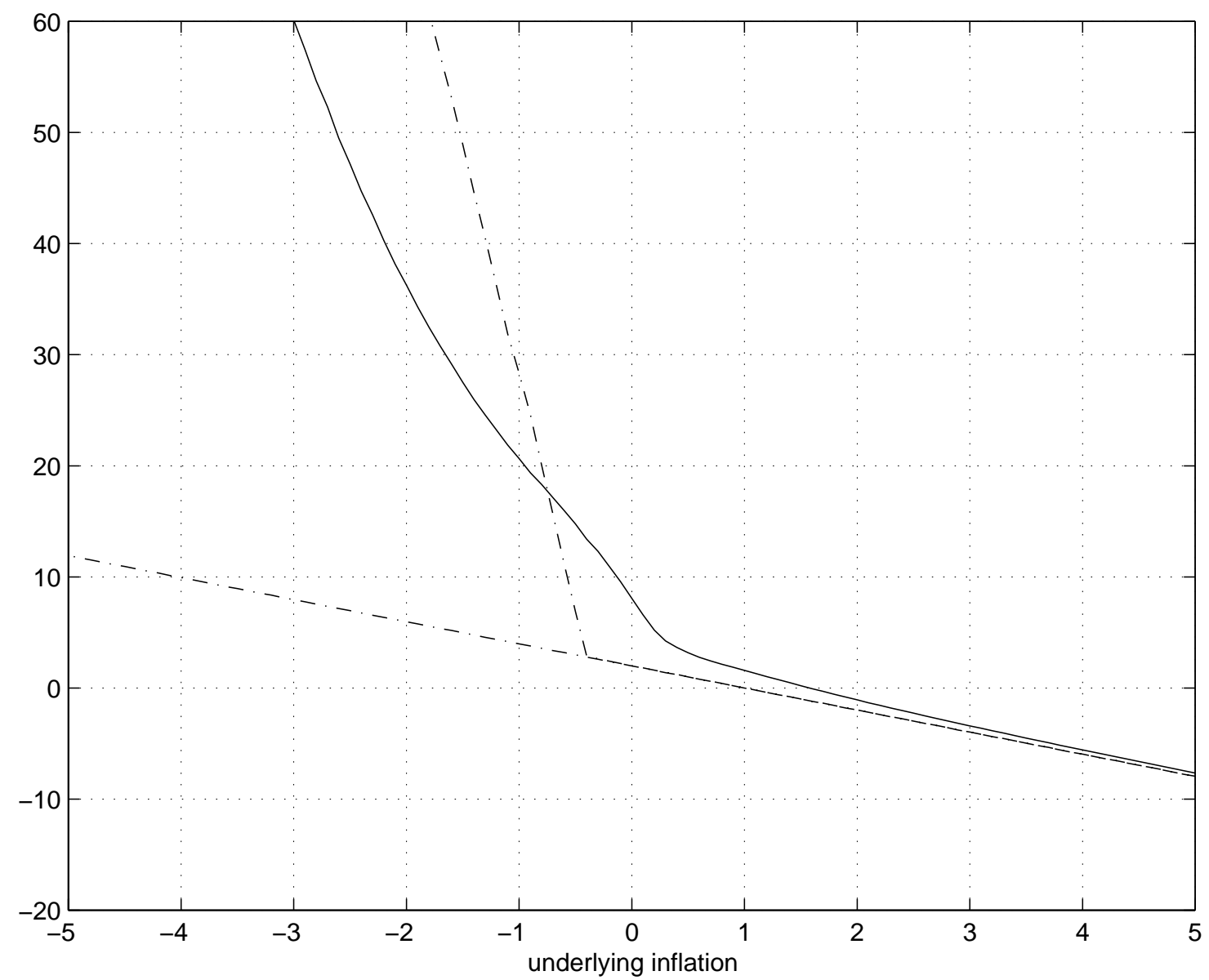

Notes: The solid line shows the optimal policy with the zero bound and uncertainty regarding policy effectiveness for our baseline parameters: $r^{*}=2, \pi^{*}=1, \sigma_{\eta}=\sigma_{\epsilon}=1$, and $\sigma_{\kappa}=0.4$ (all in percent). The dash-dot lines illustrate the corresponding deterministic benchmarks as explained in the text. 
Figure 4

\section{Optimal Interest Rate Setting}

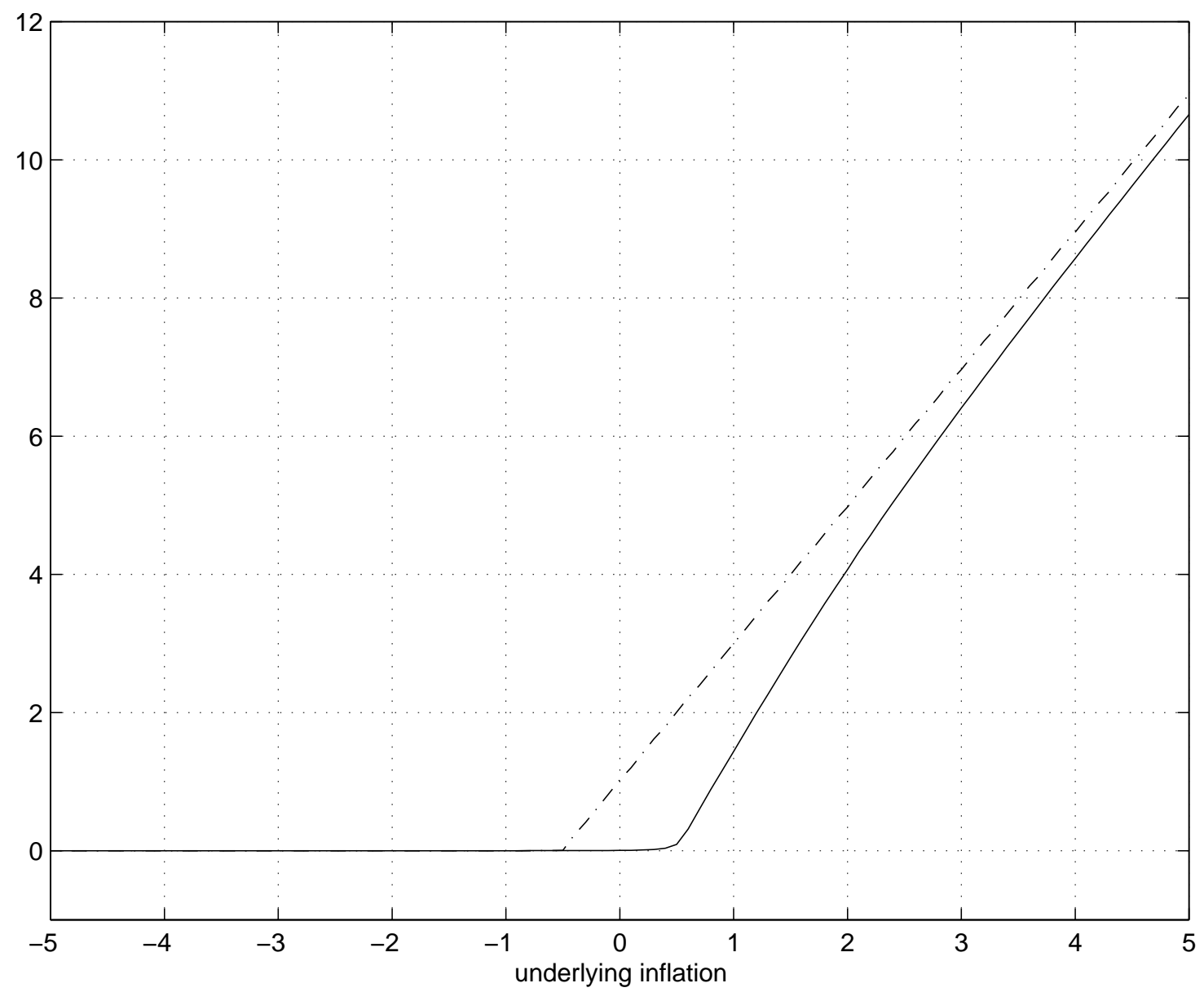

Notes: The solid line shows the optimal policy for the federal funds rate with the zero bound and uncertainty regarding policy effectiveness corresponding to the optimal policy for the Marshallian K shown in Figure 3. The dash-dot line illustrates the corresponding deterministic benchmark. 
Figure 5

\section{Optimal Interest Rate Responsiveness to Inflation}

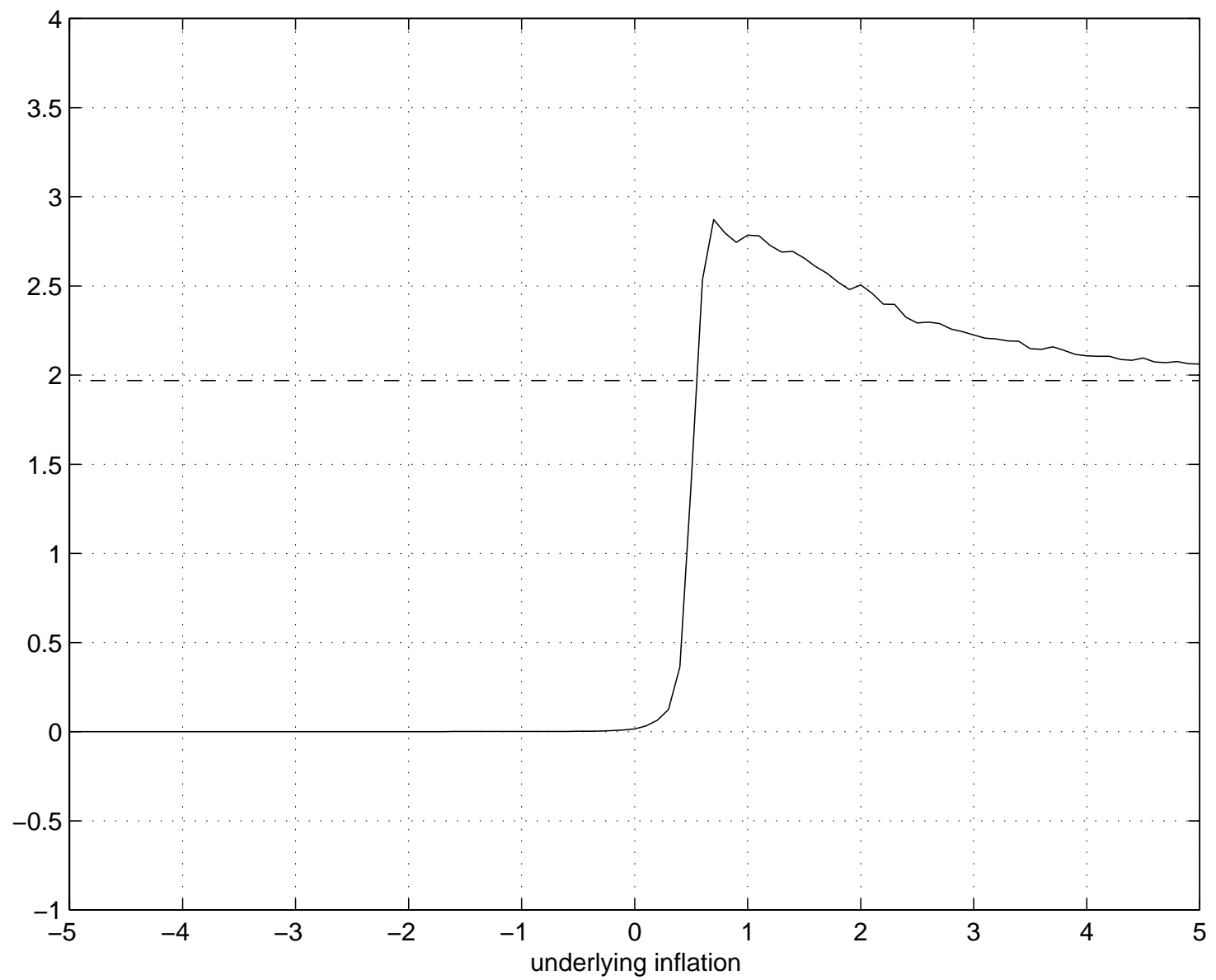

Notes: The solid line shows the slope of the federal funds rate response to inflation corresponding to the optimal policy shown in Figure 4. The dash-dot line shows the constant slope for the optimal policy with uncertainty which would obtain if the zero bound could be ignored. 
Figure 6

\section{Costly Variation in the Money Supply}
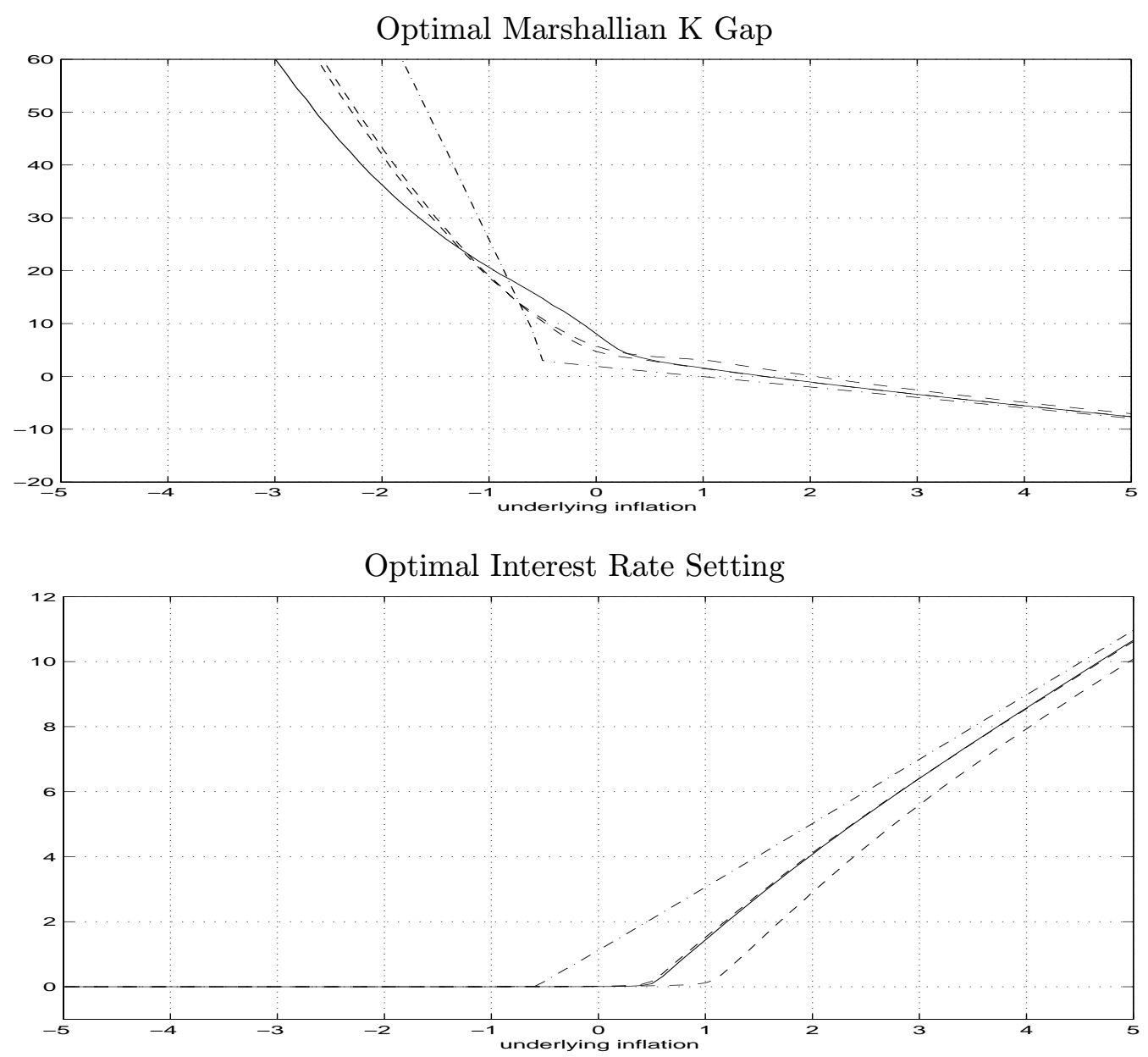

Optimal Interest Rate Responsiveness to Inflation

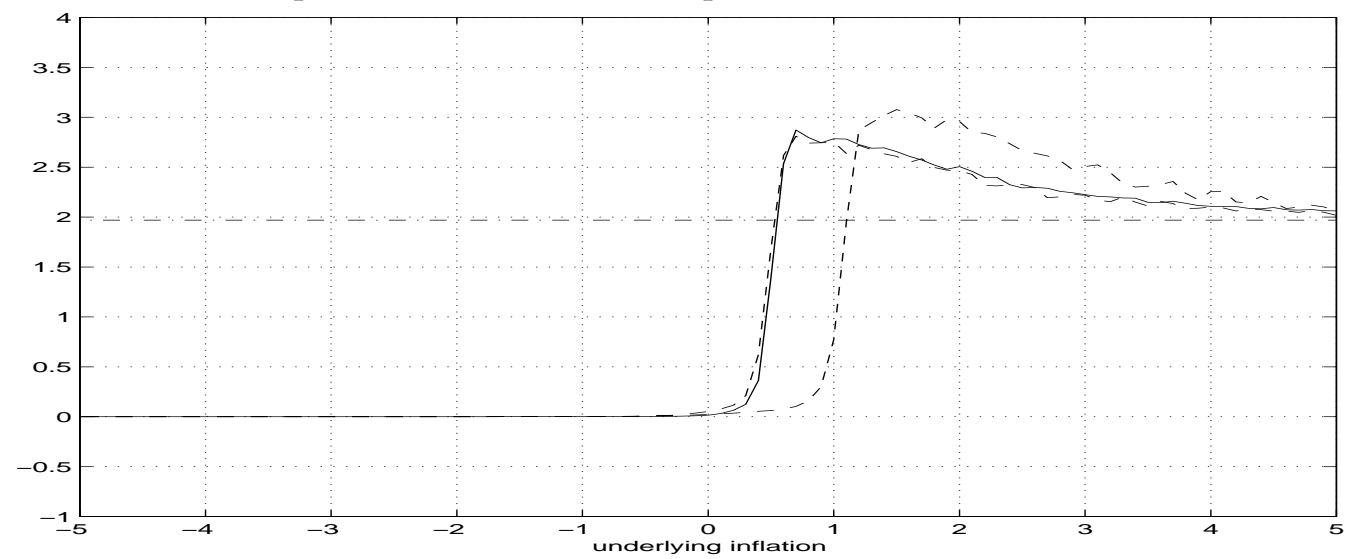

Notes: The figure compares the optimal policy with costly variation in the money supply and no uncertainty regarding policy effectiveness with $\tau=0.01$ and $\tau=0.05$ (dashed lines). The policies with and without uncertainty about $\kappa$ (solid and dash-dot lines) are repeated from the previous figures. 
Figure 7

\section{Policies for Alternative Inflation Targets}
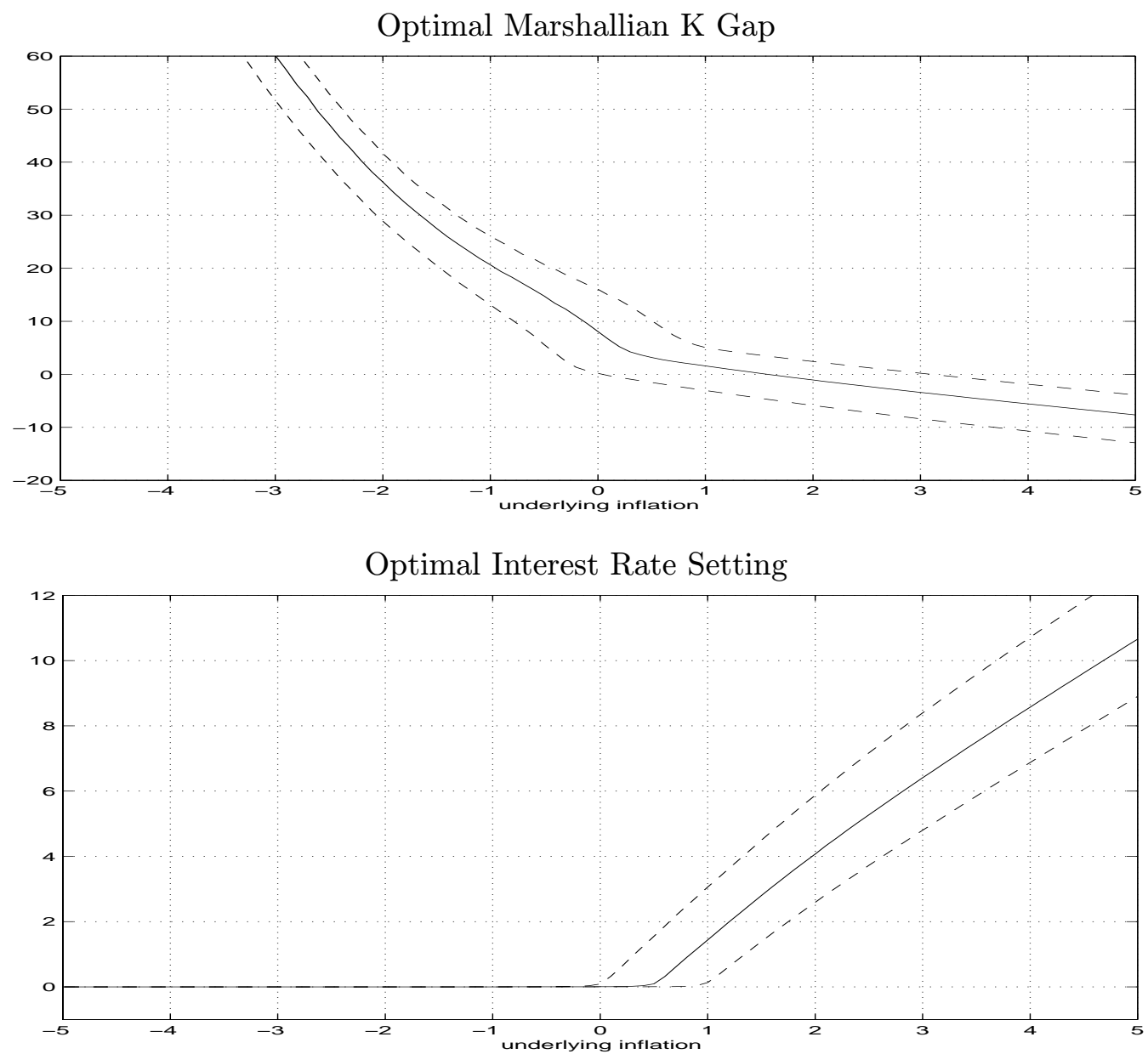

Optimal Interest Rate Responsiveness to Inflation

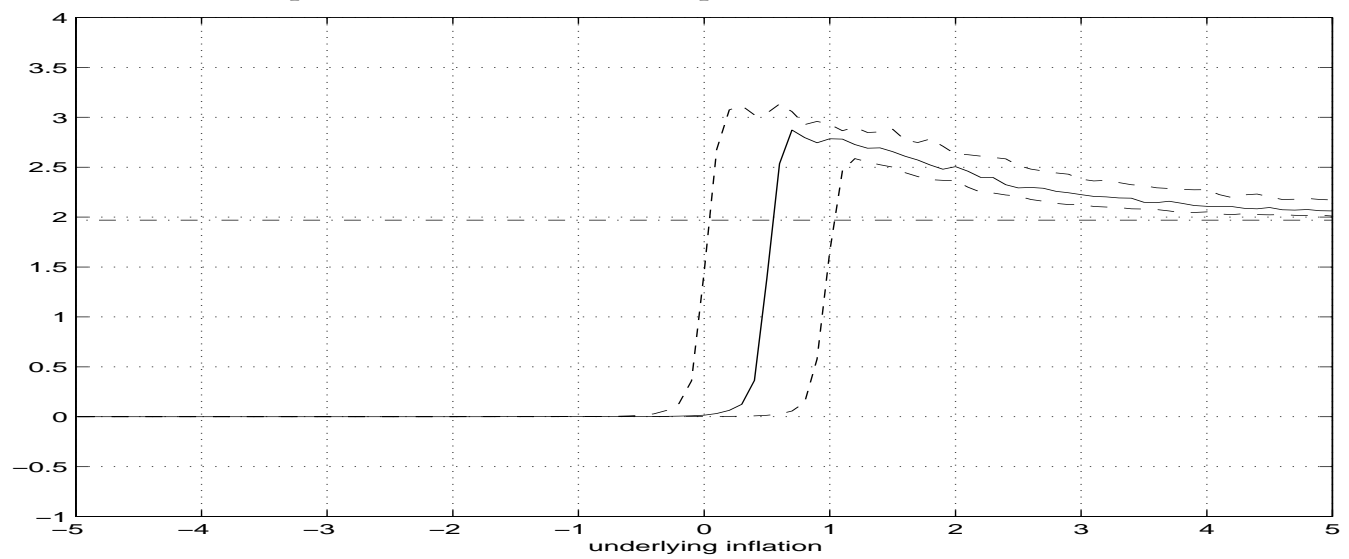

Notes: The alternatives shown are for the inflation targets $-2 \%, 1 \%$ (baseline - solid line), and $3 \%$. 
Figure 8

\section{Sensitivity to Policy Effectiveness Uncertainty}

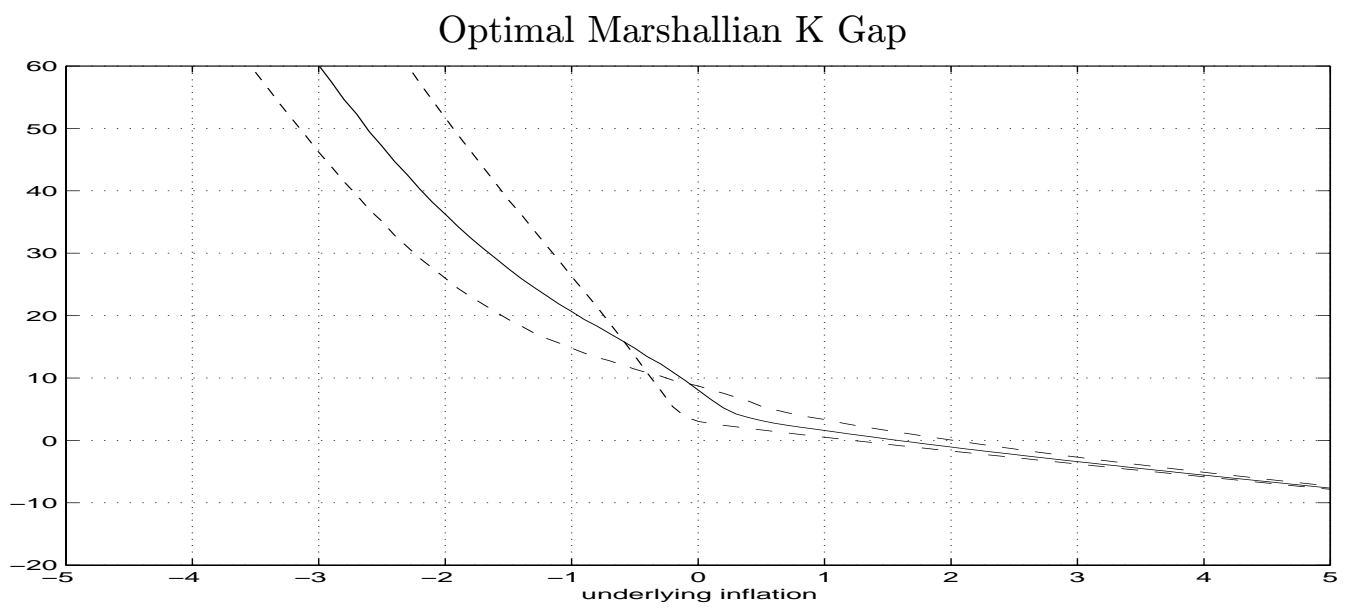

Optimal Interest Rate Setting

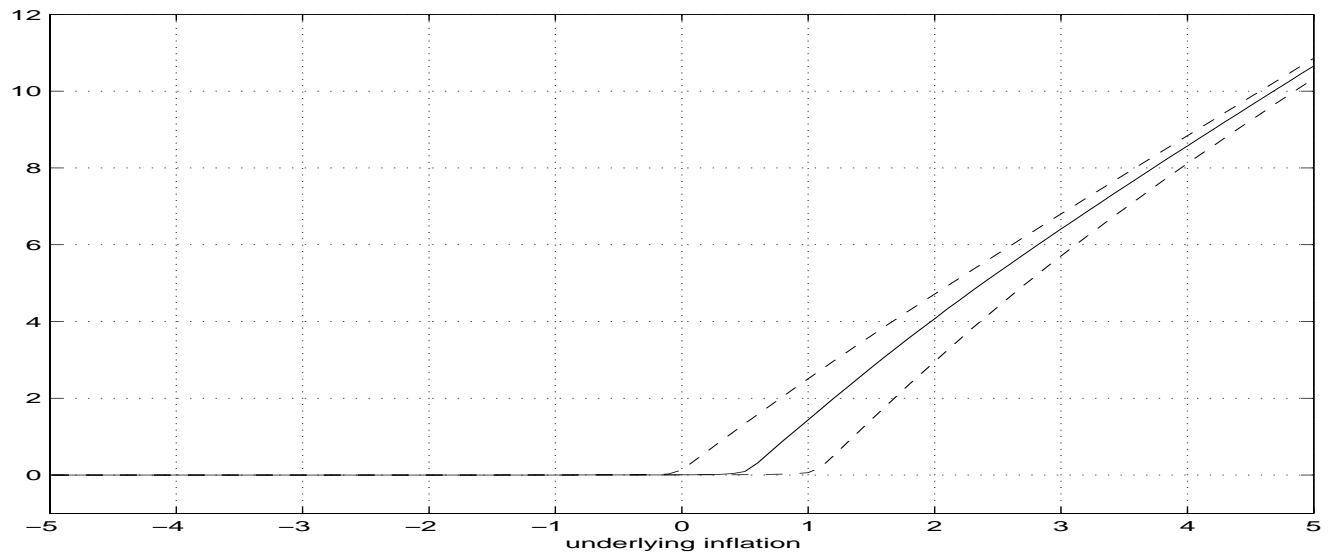

Optimal Interest Rate Responsiveness to Inflation

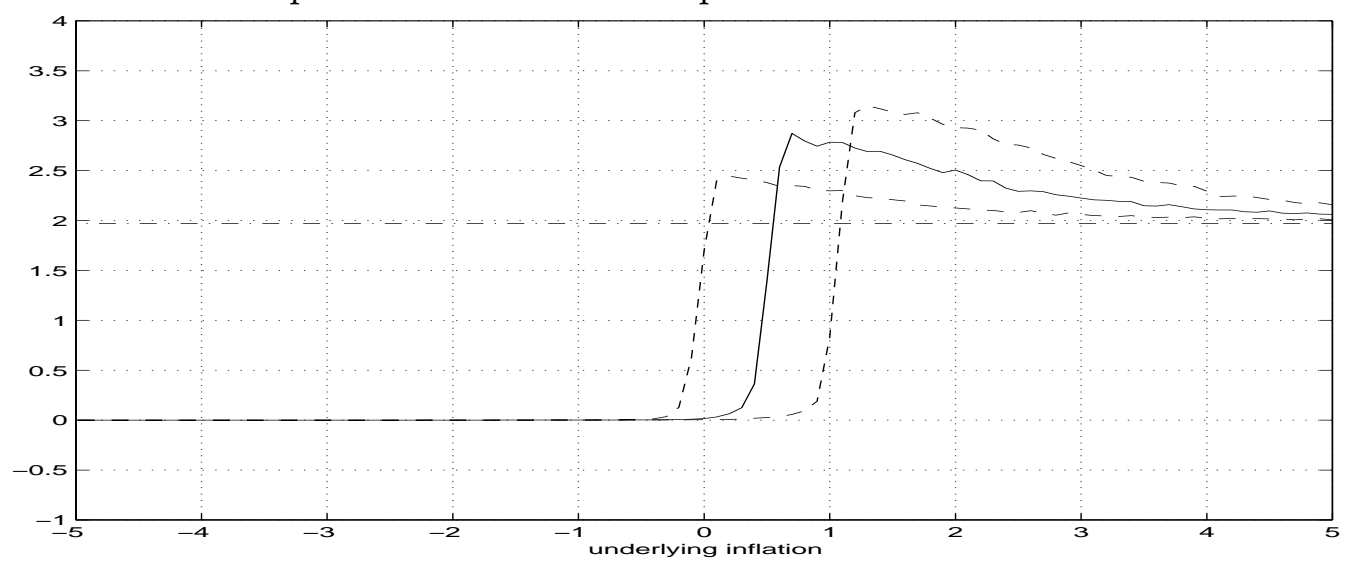

Notes: The alternatives shown for the standard deviation of $\kappa$ are $0.3,0.4$ (the baselinesolid line), and 0.5 . 
Figure 9

\section{Sensitivity to Output and Inflation Shock Uncertainty}
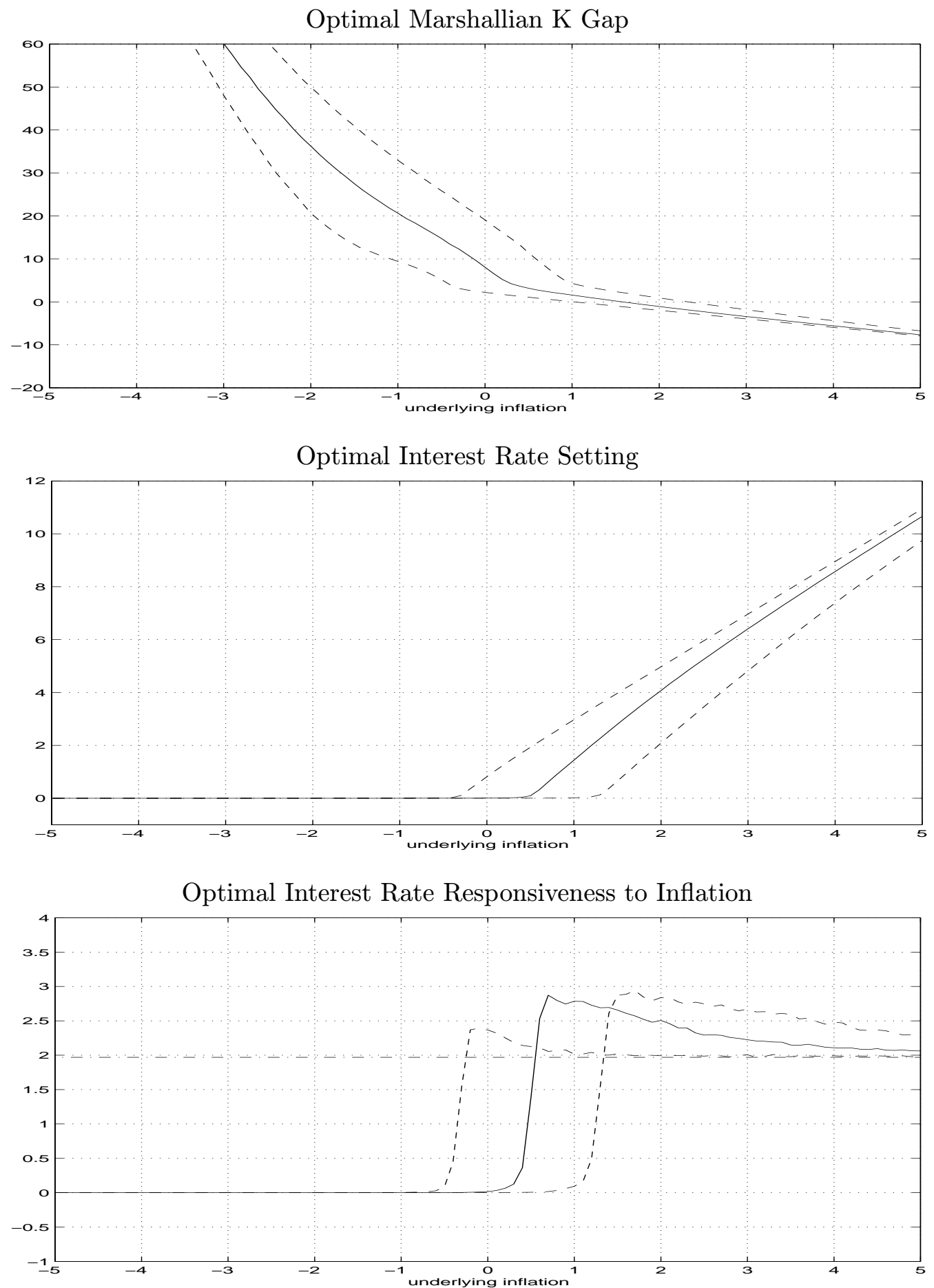

Notes: The alternatives shown for the standard deviations of $\eta$ and $\epsilon$ are 0.5, 1.0 (the baseline-solid line), and 1.5. 
Figure 10

\section{Sensitivity to Equilibrium Real Interest Rate}

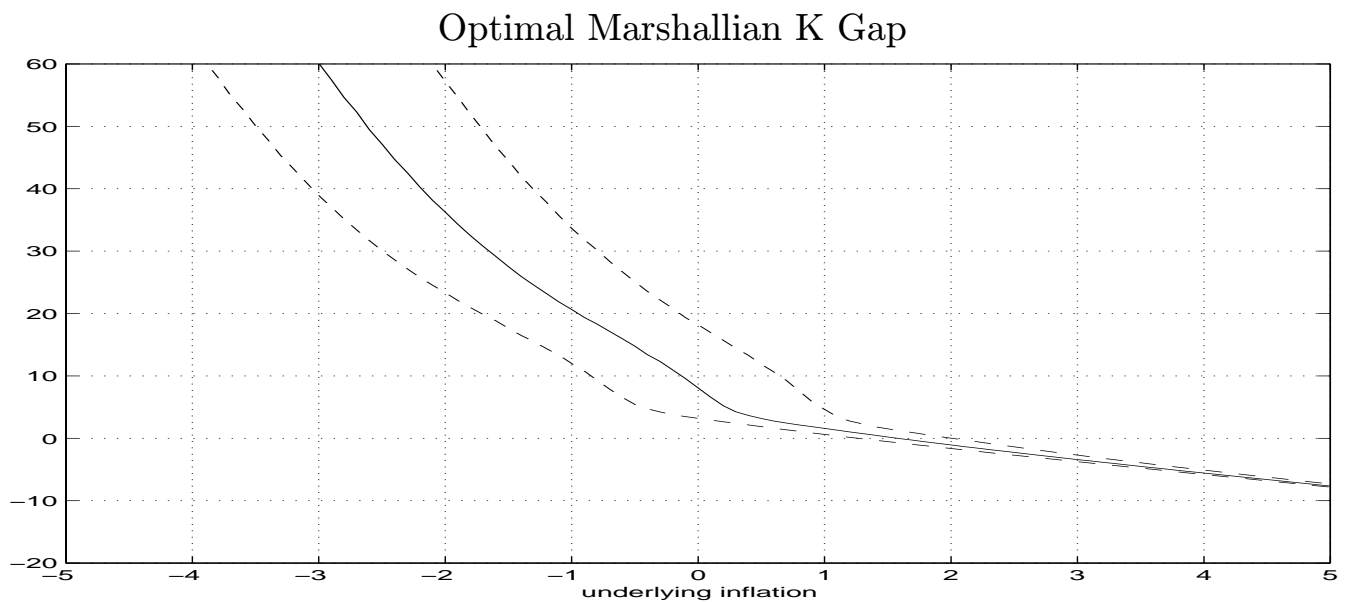

Optimal Interest Rate Setting

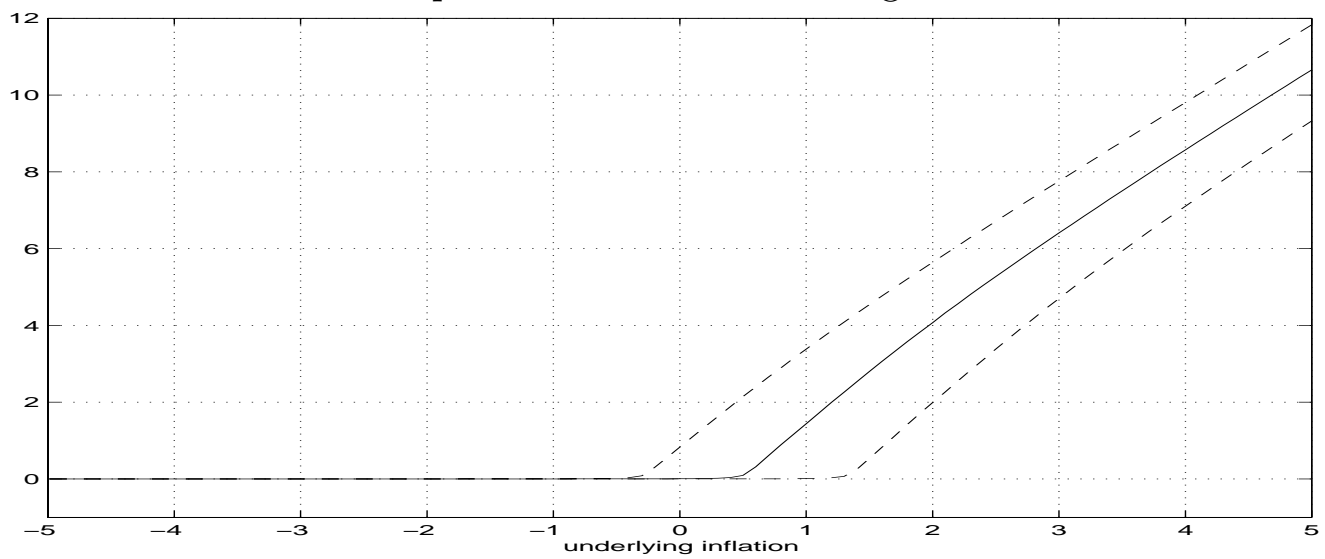

Optimal Interest Rate Responsiveness to Inflation

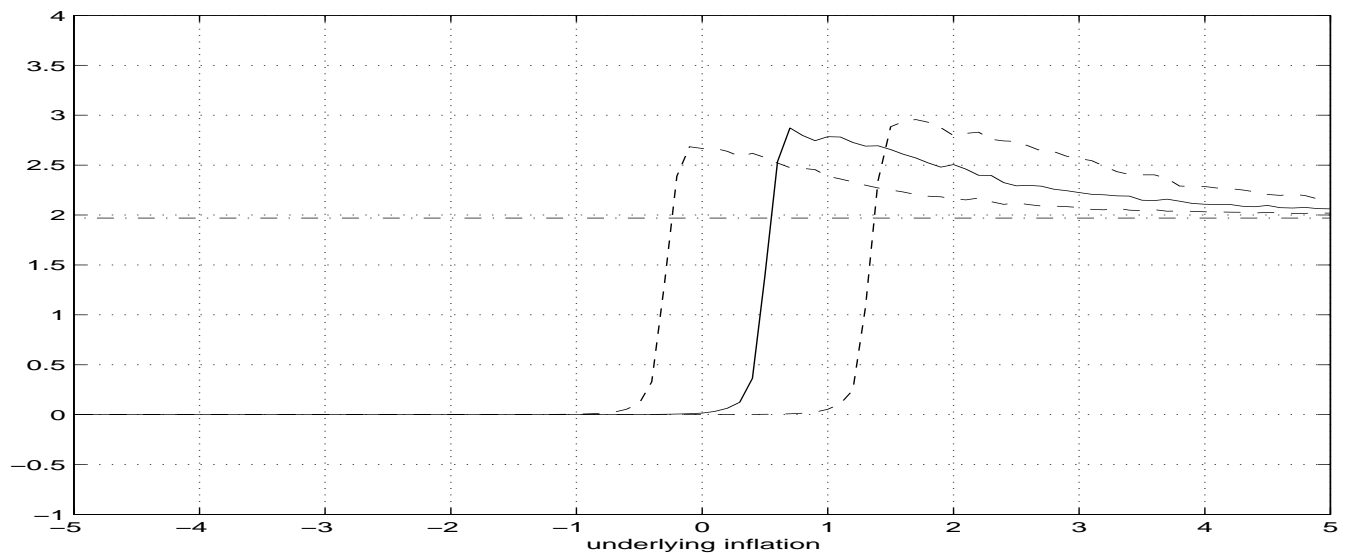

Notes: The alternatives shown for $r^{*}$ are 1.0, 2.0 (the baseline-solid line), and 3.0. 